\title{
Obstacles and Solutions for Chemical Synthesis of Syndecan-3 (53-62) Glycopeptides with Two Heparan Sulfate Chains
}

\author{
Weizhun Yang, $†$ Keisuke Yoshida,$\uparrow$ Bo Yang, $\uparrow$ Xuefei Huang*
}

\begin{abstract}
:
Proteoglycans play critical roles in many biological events. Due to their structural complexities, strategies towards synthesis of this class of glycopeptides bearing well-defined glycan chains are urgently needed. In this work, we give the full account of the synthesis of syndecan-3 glycopeptide (53-62) containing two different heparan sulfate chains. For assembly of glycans, a convergent $3+2+3$ approach was developed producing two different octasaccharide amino acid cassettes, which were utilized towards syndecan-3 glycopeptides. The glycopeptides presented many obstacles for post-glycosylation manipulation, peptide elongation, and deprotection. Following screening of multiple synthetic sequences, a successful strategy was finally established by constructing partially deprotected single glycan chain containing glycopeptides first, followed by coupling of the glycan-bearing fragments and cleavage of the acyl protecting groups.
\end{abstract}

\section{Graphical abstract}

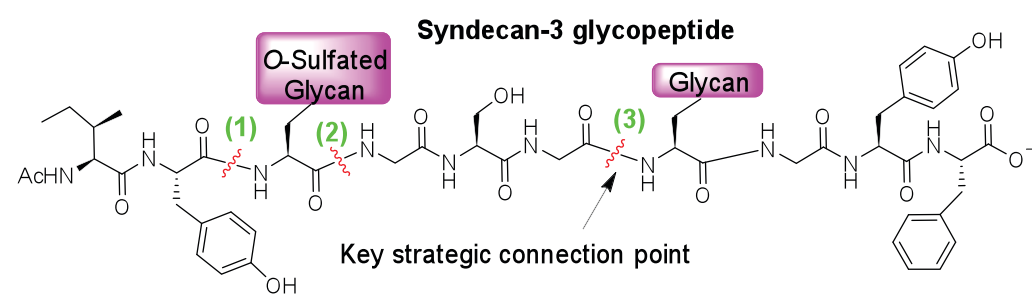

\section{Keywords:}


Carbohydrates, Glycopeptides, Glycosylation, Protecting groups, Synthesis design 


\section{Introduction}

Many naturally existing proteins contain glycan chains due to post-translational modifications..$^{1-2}$ Glycans can have broad effects on the parent peptides and proteins, ranging from tertiary structure stabilization, enhanced stability against proteolysis, to altered physiochemical properties and biological functions..$^{2-4}$ As the expression of glycans is not directly controlled by genes, glycoproteins and glycopeptides isolated from nature often exist as a heterogeneous mixture containing various glycans attached to the same peptide/protein backbone. Therefore, to decipher the structure and activity relationship, it is critical that glycoproteins and glycopeptides bearing homogeneous glycan chains can be synthesized.

Structurally, native glycoproteins are classified into two major types: $\mathrm{N}$-glycans and $\mathrm{O}$ glycans. ${ }^{2,5}$ In $\mathrm{N}$-glycans, carbohydrate residues are covalently linked to an asparagine residue in the protein backbone through an $\mathrm{N}$-acetyl glucosamine. $\mathrm{O}$-glycans can be further divided into two main classes, i.e., the mucin type and the glycosaminoglycan family proteoglycans. The mucin type $O$-glycans contain an $\mathrm{N}$-acetyl galactosamine linkage to serine or threonine, while the proteoglycan family glycopeptides share the general structure of glycosaminoglycan chains connected to a serine of the core protein typically through a tetrasaccharide linker consisted of glucuronic acid- $\beta$-1,3-galactose- $\beta$-1,3-galactose- $\beta$-1,4-xylose. ${ }^{6}$ Many creative chemical ${ }^{7-23}$ and chemoenzymatic $^{24-30}$ methods have been developed to synthesize glycopeptides bearing sophisticated structures of $N$-glycans and mucin type $O$-glycans. ${ }^{31-38}$ Great successes have been achieved in these areas with molecules approaching the sizes and complexities of native glycoproteins produced via total synthesis. ${ }^{7-9}$ In comparison, methodologies for the preparation of glycopeptides carrying homogenous glycosaminoglycan are under developed. Much synthetic work related to proteoglycans has been on the synthesis of glycosaminoglycan oligosaccharides ${ }^{39-44} 45-68$ and the tetrasaccharide linker. ${ }^{69-79}$ Recently, we have begun to develop a strategy towards the proteoglycan family glycopeptides with syndecan-3 as the target. ${ }^{80}$ With the highly complex structure, many obstacles were encountered during the synthesis. Herein, we provide the full details for the successful synthesis of syndecan-3 (53-62) glycopeptides bearing two different heparan sulfate glycan chains. 


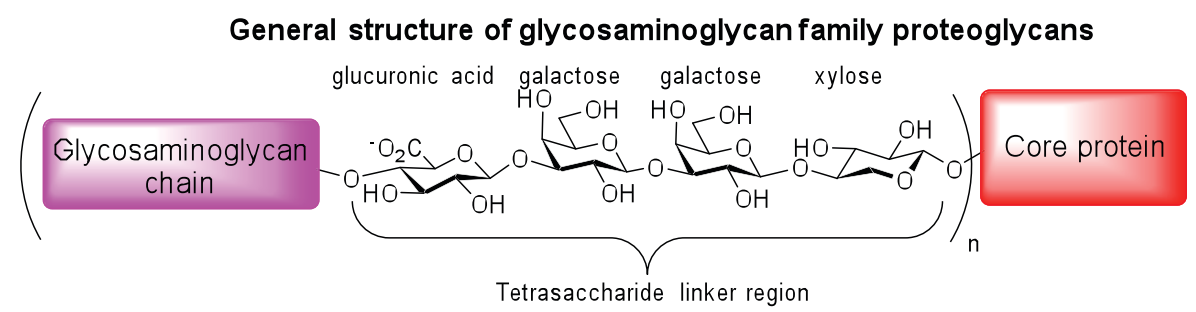

Syndecan-3 is a transmembrane proteoglycan highly expressed in neural cells with its extracellular domain bearing heparan sulfate chains. ${ }^{6,81-82}$ Syndecan-3 is involved in a wide range of biological events such as cell-cell interaction, ${ }^{83}$ skeletal muscle growth and repair, ${ }^{84-87}$ and viral infection. ${ }^{88}$ Our synthetic targets are syndecan-3 extracellular domain glycopeptides $\mathbf{1}$ and 2 (corresponding to amino acids 53-62), ${ }^{89-90}$ which contain typical structural features of heparan sulfate proteoglycans including different heparan sulfate chains, the tetrasaccharide linkers, 2-O sulfation, 6- $O$ sulfation, glucosamine $\alpha$ linked to both glucuronic acid and iduronic acid, and $N$ acetylation.

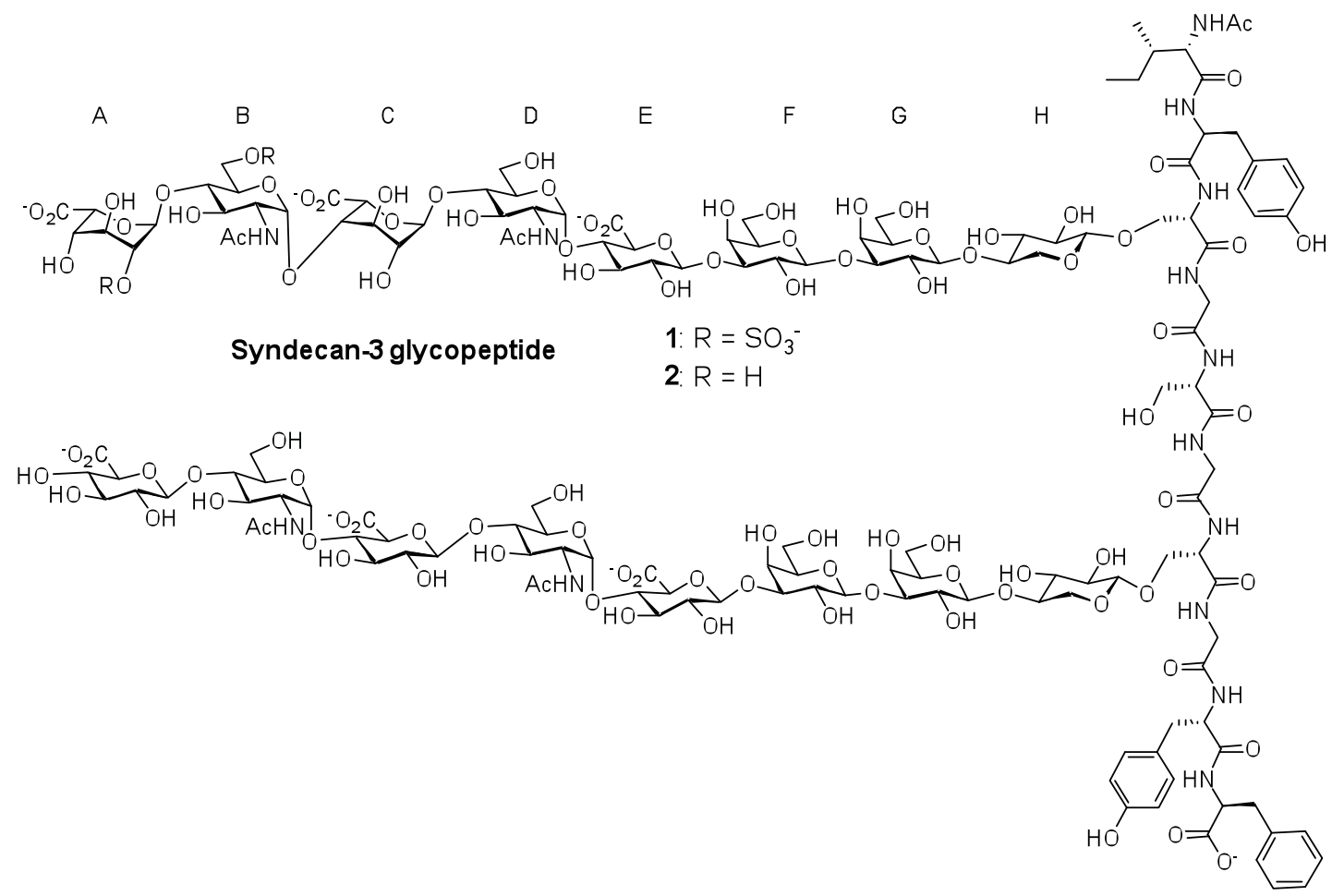

\section{Results and Discussion}

Synthetic design and preparation of iduronic acid containing octasaccharide serine cassette 
In order to prepare syndecan-3 glycopeptides, we adapted a cassette approach ${ }^{91}$ where iduronic acid containing octasaccharide serine cassette $\mathbf{3}$ and glucuronic acid containing $\mathbf{4}$ were utilized as cassettes for glycopeptide assembly. Due to the large sizes of the glycan chains in cassettes $\mathbf{3}$ and $\mathbf{4}$, we aim to develop a convergent route where oligosaccharide modules were synthesized and then joined to improve the overall synthetic efficiency.

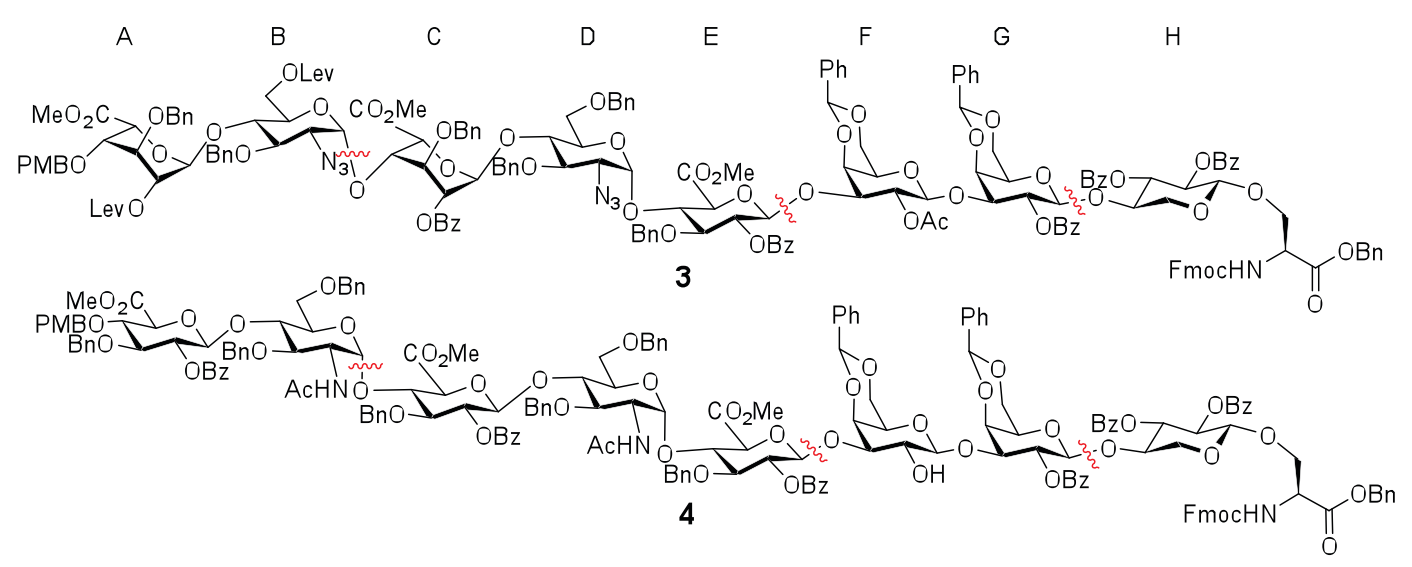

Our initial design towards the serine derivative $\mathbf{3}$ was a $2+3+2+1$ approach making the strategic disconnections of the octasaccharide at the $\mathrm{B} / \mathrm{C}, \mathrm{E} / \mathrm{F}$ and $\mathrm{G} / \mathrm{H}$ linkages. Although uronic acid thioglycosyl and trichloroacetimidate donors have been successfully utilized in glycosaminoglycan synthesis, ${ }^{92-93}$ in our experience, the corresponding hexose donors tend to give higher glycosylation yields. ${ }^{94}$ Thus, idose and glucose building blocks were used for constructing the glycosyl linkages, which would be followed by oxidation to uronic acids. ${ }^{95}$ The synthesis started from the preparation of the non-reducing end $\mathrm{AB}$ disaccharide by reacting donor 5 with acceptor $6^{53}$ The glycosylation reaction was initiated by pre-activating idosyl donor 5 with $p$-TolSOTf, ${ }^{96}$ which was formed in situ through reaction of AgOTf and $p$-TolSCl at $-78{ }^{\circ} \mathrm{C}$ (Scheme 1a). Following complete activation of the donor $\mathbf{5}$, acceptor $\mathbf{6}$ was added to the reaction mixture together with a non-nucleophilic base tri-'butyl-pyrimidine (TTBP). ${ }^{97}$ Unfortunately, no desired disaccharide 7 was obtained. Analysis of the reaction mixture showed that most acceptor 6 was recovered $(\sim 63 \%)$ with the major side product as the 1,6-anhydro idoside $8(\sim 60 \%)$. The 1,6-linkage in $\mathbf{8}$ was presumably formed by nucleophilic attack of the anomeric center upon donor activation by 6- $O$ due to the electron rich 6- $O$ - $p$-methoxybenzyl (PMB) moiety. To address this problem, we tested donor 9 bearing the 6- $O$ - ${ }^{\text {butyldimethylsilyl }}$ (TBS) group in reaction with acceptor $\mathbf{6}$, which gave the 1,6-anhydro sugar $\mathbf{1 0}$ as the major side 
product. To reduce the remote participation by the 6-O moiety, the tbutyldiphenylsilyl (TBDPS) group was examined next as the protective group (donor 11). Gratifyingly, the TBDPS ether was sufficiently bulky, which effectively suppressed the 1,6-anydro sugar formation leading to $61 \%$ yield of the desired disaccharide 13 along with 7\% of the epimer 14 (Scheme 1b). The Ac and $\mathrm{Bz}$ groups in 13 were then exchanged with levulinate (Lev) as sites for future $O$-sulfation producing disaccharide donor 15 (Scheme 1c). The TBDPS moiety from 15 was removed and the free hydroxyl group oxidized by 2,2,6,6-tetramethyl-1-piperidinyloxy (TEMPO) and [bis(acetoxy)iodo]benzene (BAIB) ${ }^{92}$ followed by benzyl ester formation with phenyl diazomethane ${ }^{95}$ (donor 16).

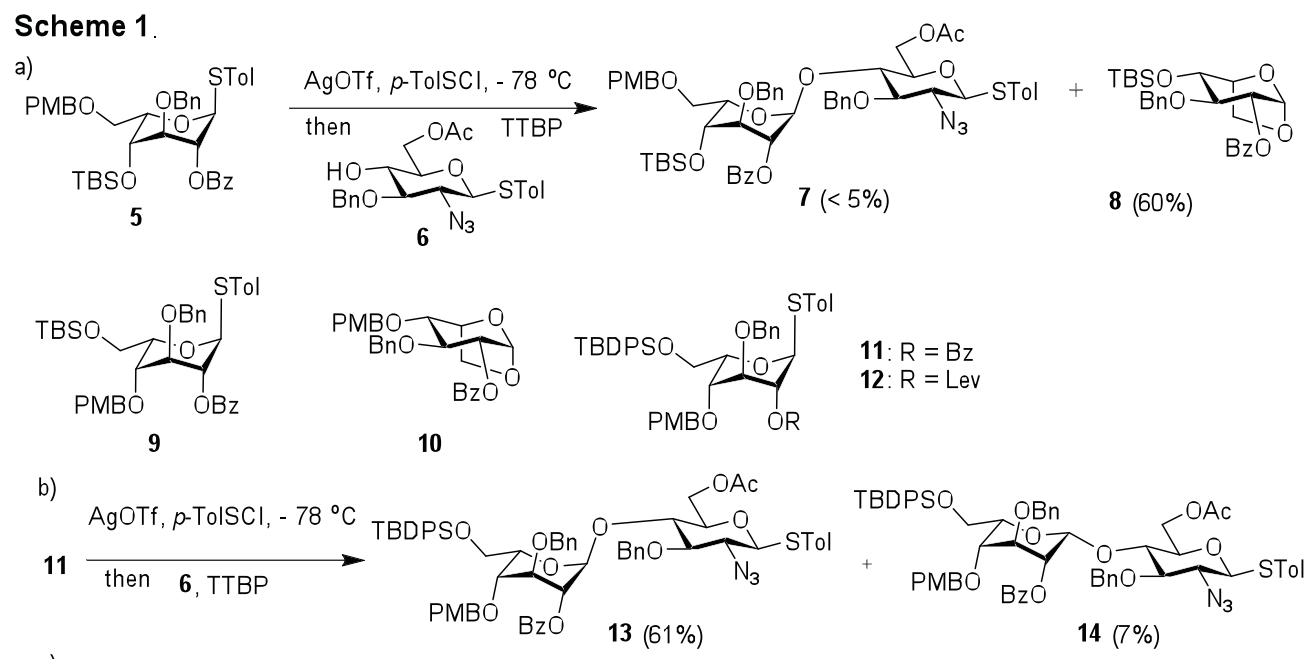

c)

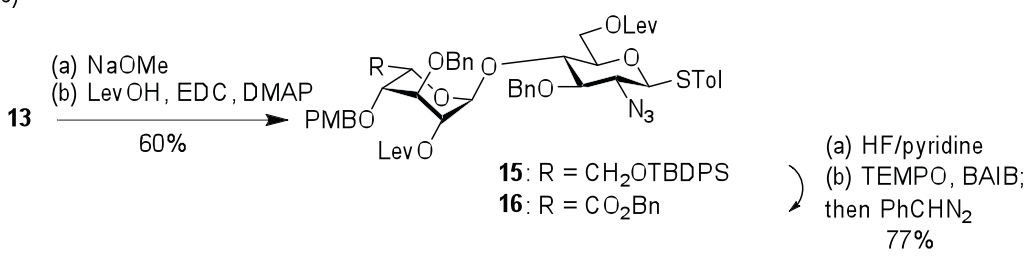

With the $\mathrm{AB}$ module in hand, we moved onto the preparation of the $\mathrm{CDE}$ and FG modules. The $\alpha$-linked disaccharide acceptor $\mathbf{1 8}^{53}$ was successfully glycosylated by the idosyl donor $\mathbf{1 7}$ producing CDE trisaccharide $\mathbf{1 9}$ in $\mathbf{8 5} \%$ yield (Scheme 2a). The FG di-galactoside $\mathbf{2 0}$ was synthesized by reacting di-Lev galactosyl donor $\mathbf{2 1}^{98}$ with galactoside $\mathbf{2 2}^{98}$ followed by hydrazine acetate treatment to selectively remove the Lev groups (Scheme 2b). Trisaccharide 19 was then joined with di-galactoside acceptor 20 forming CDEFG pentasaccharide module 24 in 65\% yield (Scheme $\mathbf{2 c}$ ). The azide moiety in $\mathbf{2 4}$ was converted to acetamide and the product was further transformed to acceptor $\mathbf{2 5}$. The non-reducing end hydroxyl group of $\mathbf{2 5}$ was 
protected with Lev generating CDEFG pentasaccharide donor 26. The hindered 2'-OH in 25 did not undergo acylation under the reaction condition as it was flanked by two bulky glycan rings.

Scheme 2.
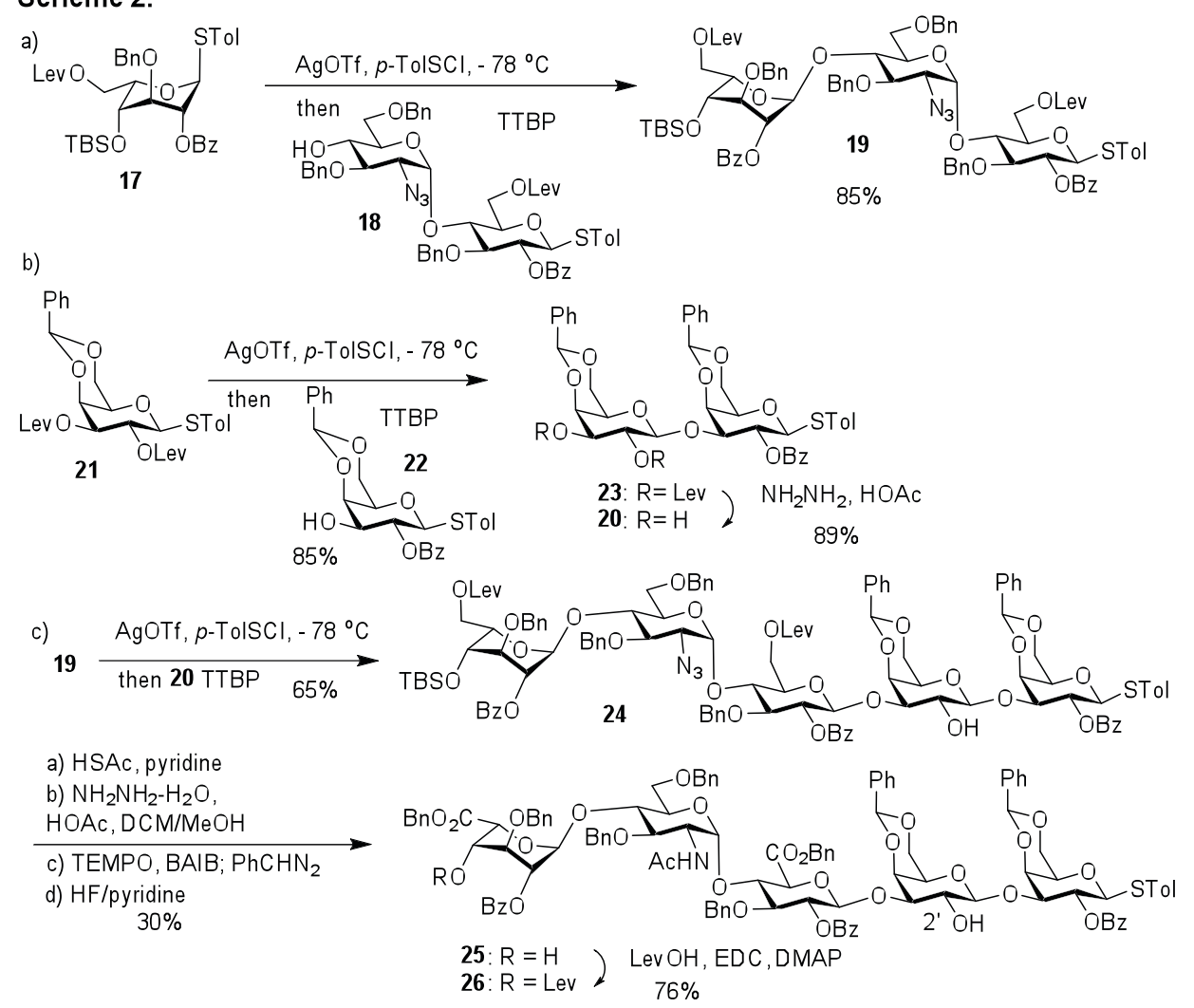

Merging the $\mathrm{AB}$ and $\mathrm{CDEFG}$ modules turned out to be highly problematic. Reaction of donor 16 with pentasaccharide acceptor 25 failed to lead to any desired heptasaccharide 27 (Scheme 3a). To test the possibilities of acetamide ${ }^{99}$ or the electron withdrawing benzyl ester groups negatively impacting glycosylation, donor 15 and idose/azide bearing thioglycosyl trisaccharide acceptor $\mathbf{2 8}$ were examined, which did not lead to successful glycosylation either. Several side products due to acceptor activation were observed from these reactions. To avoid acceptor activation, hexasaccharide acceptor $\mathbf{3 0}$ was prepared by reacting $\mathbf{2 6}$ with xylosyl serine 29 followed by Lev removal (Scheme 3b). Although the yield was not high ( 20\%), sufficient quantity of hexasaccharide $\mathbf{3 0}$ was acquired. However, reaction of $\mathbf{1 6}$ with $\mathbf{3 0}$ again did not provide the desired octasaccharide 31 (Scheme 3c). These unsuccessful attempts suggest that it is difficult to form the $\mathrm{BC}$ glycosyl linkage using oligosaccharide building blocks. 

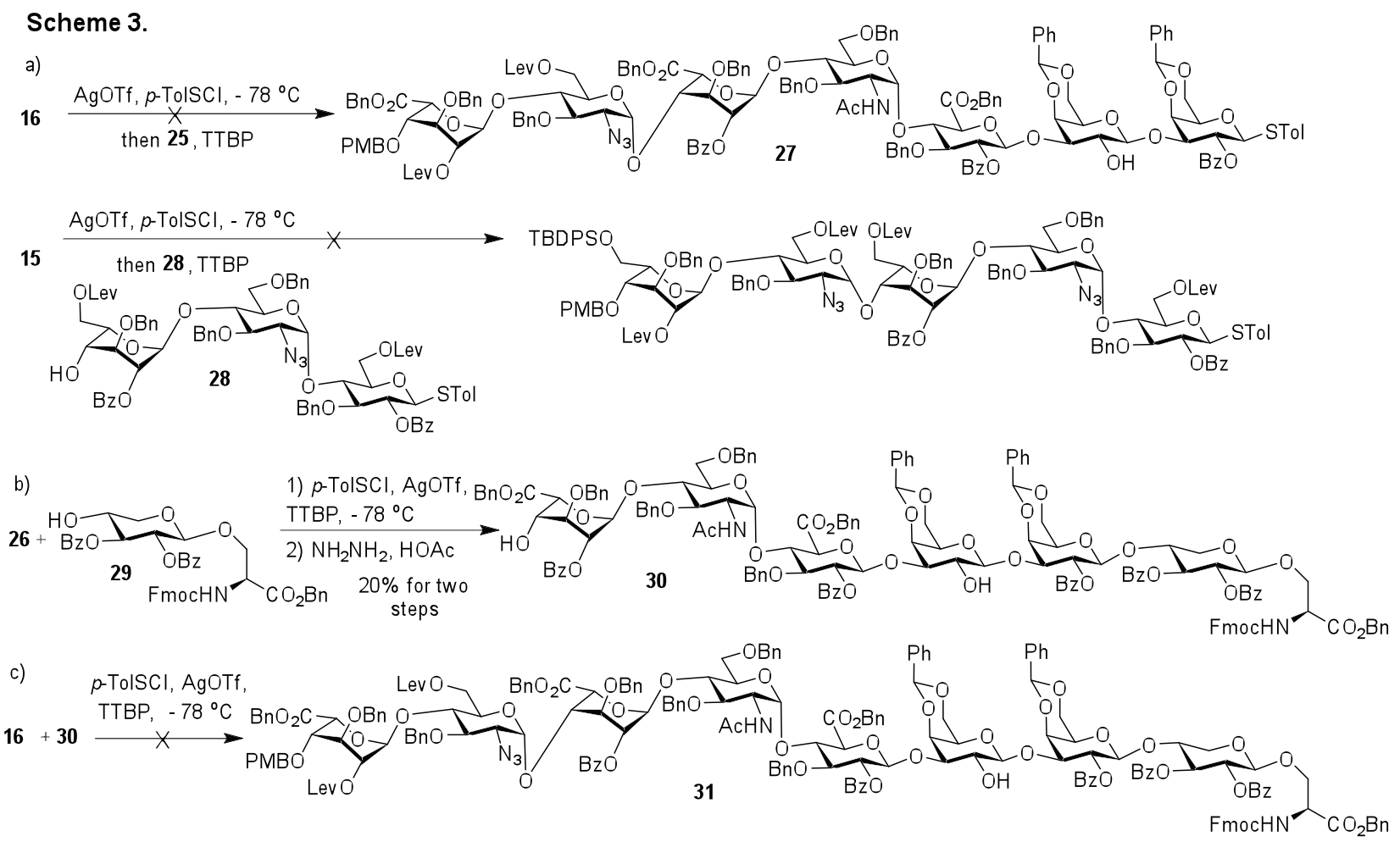

To overcome the aforementioned difficulty, a second generation approach was designed to avoid the late stage formation of the B/C linkage by adapting a 3+2+3 strategy using building blocks consisted of ABC trisaccharide, DE disaccharide and FGH trisaccharide. To form the key B/C linkage, glycosylation of idosyl acceptor $\mathbf{3 3}$ by glucosamine donor $\mathbf{3 2}$ was carried out (Scheme 4a). Gratifyingly, this reaction proceeded smoothly, forming the BC disaccharide $\mathbf{3 4}$ in $80 \%$ yield with the $\alpha$ anomer as the sole stereoisomer isolated. The stereochemistry of the newly formed glycosidic linkage was confirmed by NMR analysis $\left({ }^{1} \mathbf{J}_{\mathrm{Cl}}{ }^{\prime}-\mathrm{Hl}{ }^{\prime}=169 \mathrm{~Hz}\right)$. ${ }^{100}$ The low reactivities of the oligosaccharide building blocks such as 16, 26 and 28 are presumably due to electron withdrawing power and/or steric hindrance associated with the additional glycan rings. ${ }^{101-103}$ Protective group manipulation of $\mathbf{3 4}$ produced disaccharide acceptor $\mathbf{3 5}$, which was glycosylated by the idosyl donor 12 giving ABC trisaccharide 36 (Scheme 4b). The DE disaccharide $\mathbf{4 0}$ was formed by reaction of azido glucoside donor $\mathbf{3 7}$ with glucoside $\mathbf{3 8}$ followed by protective group adjustment (Scheme $\mathbf{4 c}$ ). In order to avoid the remote participation by the 6$O$-PMB moiety in future glycosylation, the PMB group in 39 was replaced with TBDPS (disaccharide 40). The reducing end FGH trisaccharide module was prepared by glycosylating the xylosyl serine 29 with galactoside donor $41^{98}$ leading to disaccharide $\mathbf{4 2}$ in $81 \%$ yield 
(Scheme 4d). This yield was significantly higher than that for the formation of 30, again suggesting higher reactivity of monosaccharide building blocks compared to the corresponding oligosaccharide donor. The Lev group in $\mathbf{4 2}$ was removed, which subsequently underwent glycosylation with galactoside donor $\mathbf{2 1}$ followed by hydrazine treatment to generate FGH trisaccharide 44.

\section{Scheme 4.}

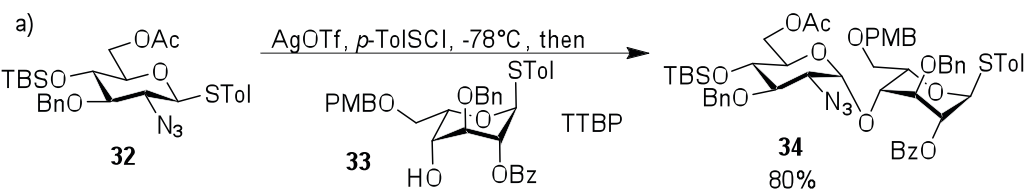
(a) $\mathrm{Mg}(\mathrm{OMe})_{2}, \mathrm{DCM},-20^{\circ} \mathrm{C}-0^{\circ} \mathrm{C}$
(b) LevOH, EDC-HCI,DMAP
(c) DDQ, DCM/ $\mathrm{H}_{2} \mathrm{O}$
(d) HF/Pyridine
(e) TBDPSCI, imidazole
$44 \%$

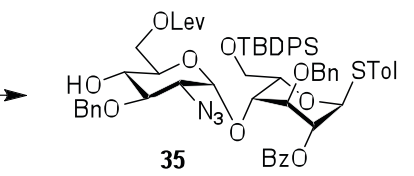

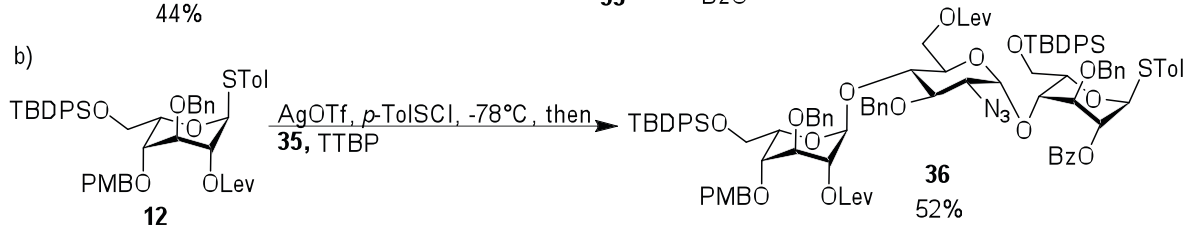
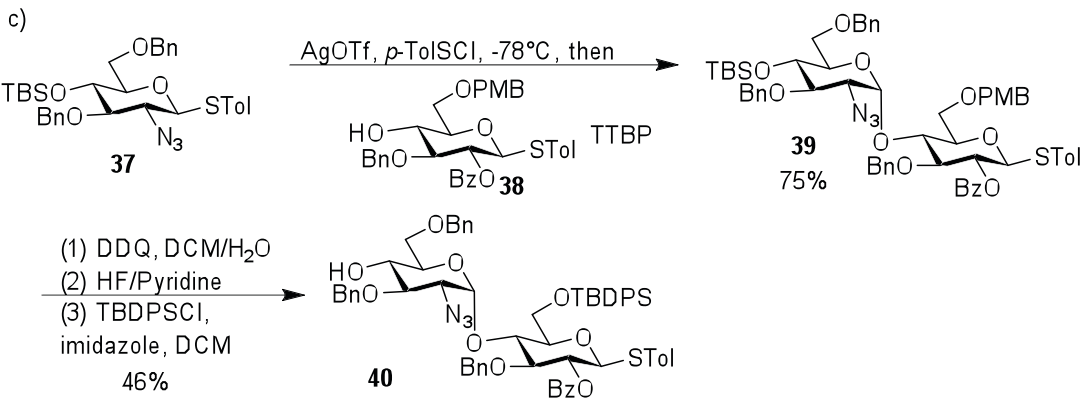

d)
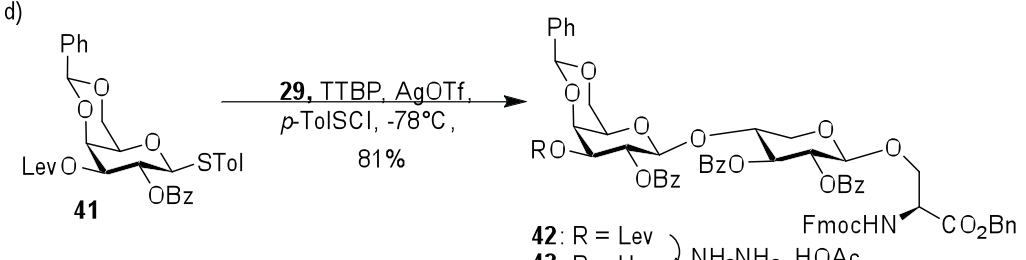

42: $\mathrm{R}=\mathrm{Lev} \quad 2 \mathrm{NH}_{2} \mathrm{NH}_{2}, \mathrm{HOAC}$

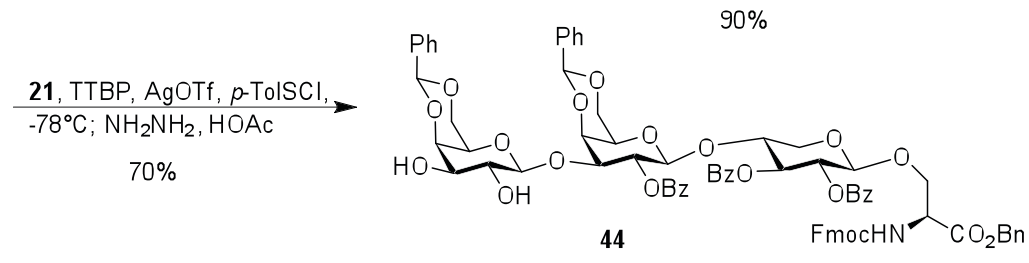

With the three modules prepared, their union was tested next (Scheme 5). Under the preactivation condition, glycosylation of disaccharide DE acceptor $\mathbf{4 0}$ by $\mathrm{ABC}$ trisaccharide donor 
36 led to pentasaccharide $\mathbf{4 5}$ in an excellent 93\% yield. Pentasaccharide $\mathbf{4 5}$ was a competent donor, successfully glycosylating the FGH trisaccharide module $\mathbf{4 4}$ and producing the octasaccharide module 46. The successful assembly of $\mathbf{4 6}$ indicates that the $\mathrm{C} / \mathrm{D}$ and $\mathrm{E} / \mathrm{F}$ linkages are suitable strategic linkage points for constructing the octasaccharide module. In order to prepare the compound $\mathbf{3}$, glycosyl serine $\mathbf{4 6}$ was de-silylated followed by oxidation of the three newly freed hydroxyl groups to carboxylic acids, methyl ester formation and acetylation. Elevated reaction temperature and excess acetic anhydride were necessary for acetylation due to the low reactivity of the free hydroxyl group in $\mathbf{4 6}$.

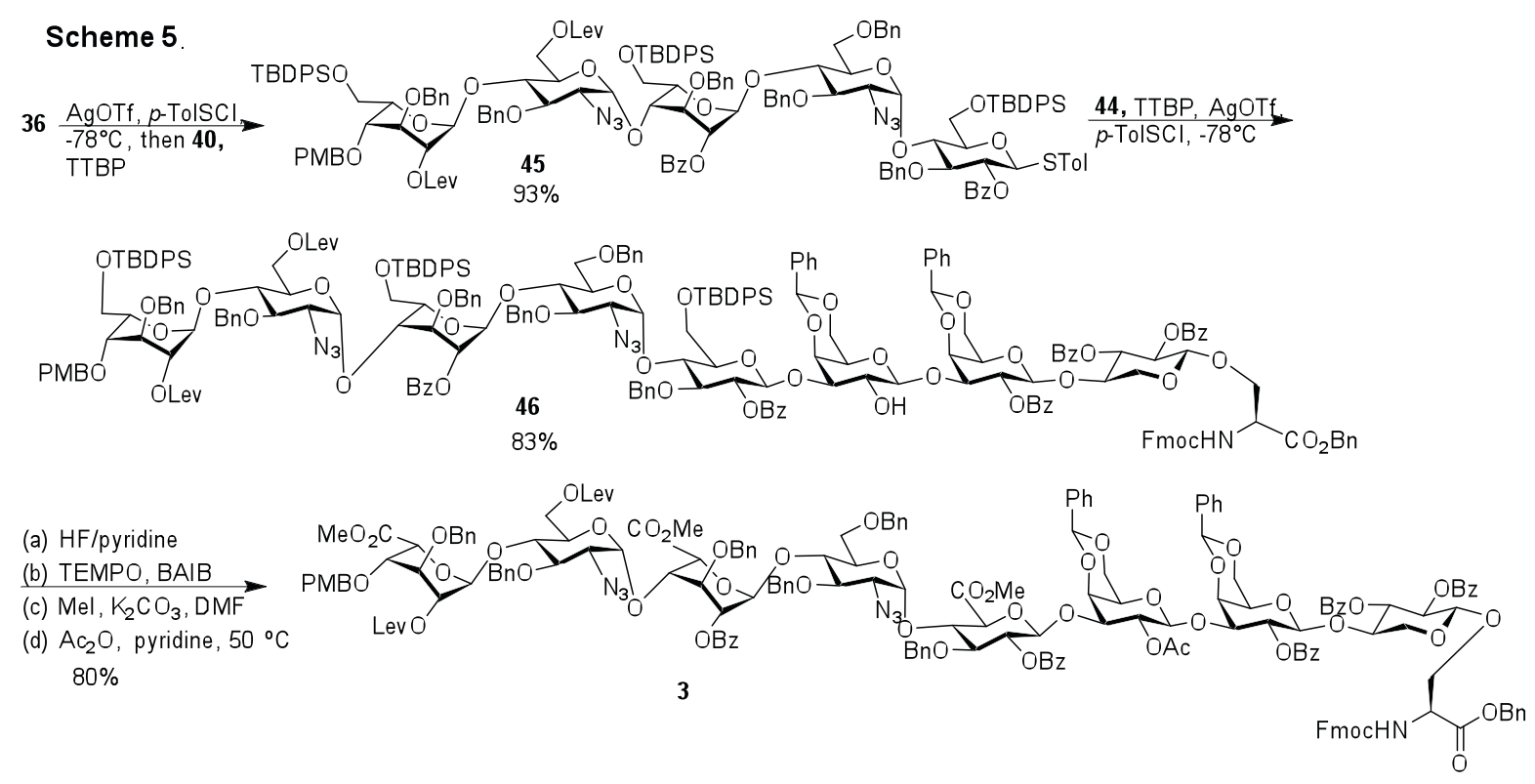

\section{Assembly of the glucuronic acid containing octasaccharide serine cassette 4}

With the knowledge gained in preparing octasaccharide $\mathbf{3}$, the octasaccharide serine cassette 50 was synthesized following the same $3+2+3$ approach (Scheme 6). The glucoside donor 47, pre-activated by $p$-TolSCl/AgOTf, glycosylated disaccharide 40 generating $\mathrm{ABC}$ trisaccharide 48 in $85 \%$ yield. The $3+2$ glycosylation between trisaccharide 48 and disaccharide 40 went smoothly producing pentasaccharide 49, which subsequently glycosylated the trisaccharide serine unit $\mathbf{4 4}$ leading to the octasaccharide cassette $\mathbf{5 0}$ in an excellent $87 \%$ yield. The successful preparation of octasaccharide $\mathbf{5 0}$ demonstrated the generality of the $3+2+3$ route. The TBDPS silyl ether groups in $\mathbf{5 0}$ were removed by HF/pyridine to expose the three primary hydroxyls, which were oxidized to carboxylic acids ${ }^{92}$ and subsequently converted to methyl 
esters. The two azide groups were transformed to $N$-acetyl moieties through a one pot reduction/acetylation procedure ${ }^{104}$ to afford octasaccharide 4.

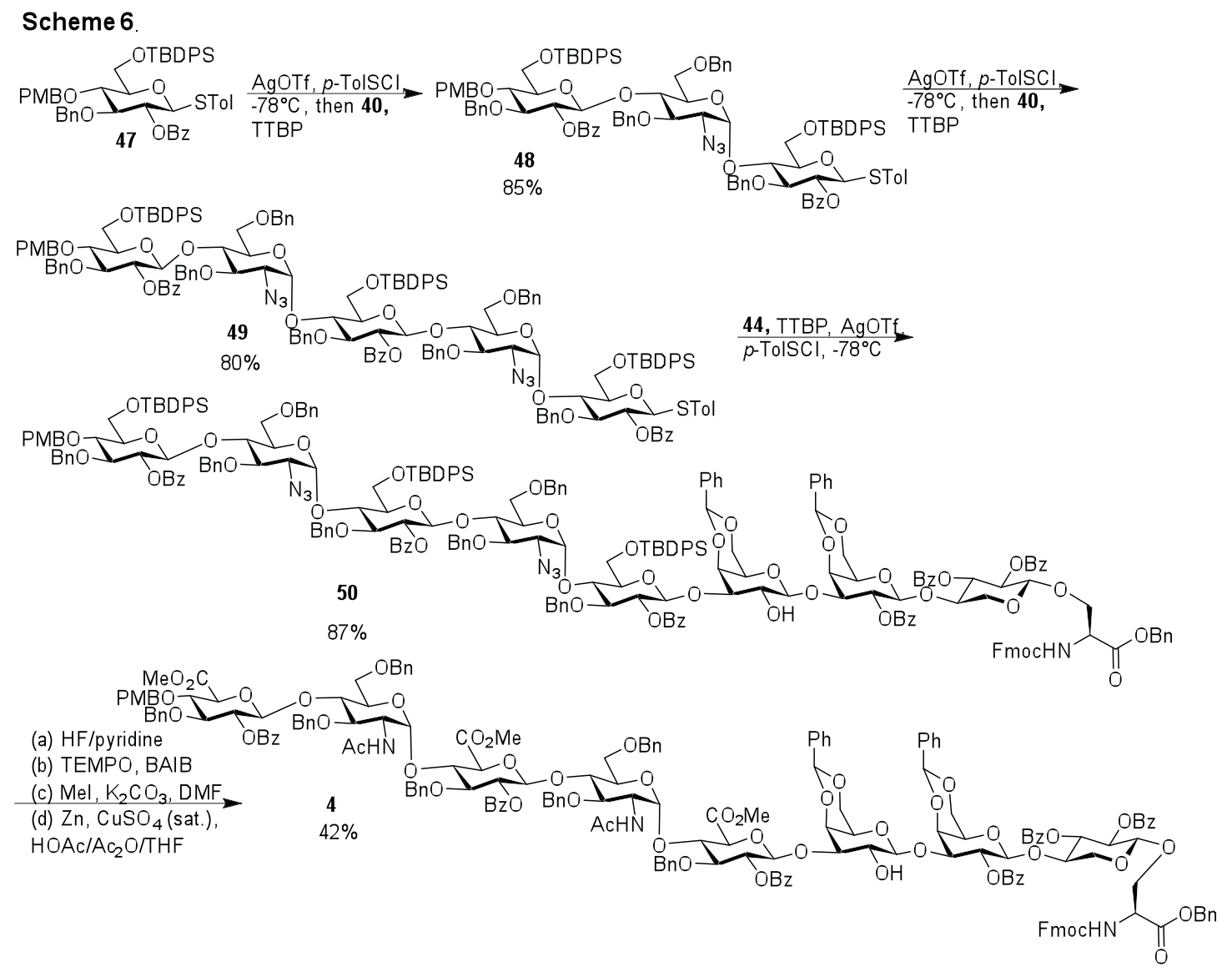

\section{Obstacles in glycopeptide synthesis}

The glycopeptide assembly was explored next. With the high sensitivity of $O$-sulfates to acid and the propensity of the glycopeptide to undergo base promoted $\beta$-elimination, ${ }^{105-107}$ common amino acid side chain protective groups such as Boc and trityl should be avoided and the sequence and condition of deprotection need to be optimized.

To test the deprotection condition, octasaccharide 4 was treated with piperidine ${ }^{108}$ to remove the $N$-terminal Fmoc followed by coupling with glycine $\mathbf{5 1}$ and catalytic hydrogenolysis to produce glycopeptide 52 (Scheme 7a). The next step was transesterification using $\mathrm{NaOMe} / \mathrm{MeOH}(\sim \mathrm{pH} 9.5)$ to remove the Ac and $\mathrm{Bz}$ groups. Although this condition was previously successfully applied to an iduronic acid containing octasaccharide module 54, multiple fragments from backbone cleavages at non-reducing ends of glucuronic acids of $\mathbf{5 3}$ 
were observed based on mass spectrometry analysis. The higher lability of glycopeptide $\mathbf{5 3}$ to base treatment was possibly because the 4-O can coordinate with $\mathrm{Na}^{+}$ion thus bringing the $\mathrm{NaOMe}$ closer to the acidic axial proton on the adjacent C-5 center (Scheme 7b). This in turn can facilitate the removal of the H-5 arranged in 1,2-cis geometry to the 4-O. Neighboring group assisted glycan cleavages are known..$^{51,109}$

\section{Scheme 7.}

a) (a) piperidine; then HATU

4 DIPEA, 51, DME

(b) $\mathrm{H}_{2}, \mathrm{Pd} / \mathrm{C}$,

$\mathrm{CH}_{2} \mathrm{Cl}_{2} / \mathrm{MeOH}$;

$\mathrm{AcHN} \underbrace{\stackrel{O}{\mathrm{O}}}_{51} \mathrm{OH}$
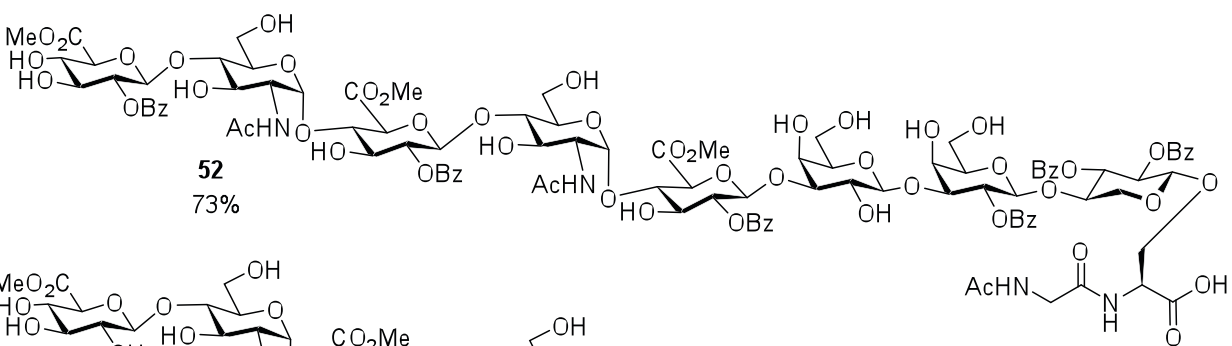

$\mathrm{NaOMe}, \mathrm{MeOH}$ $\mathrm{pH}=9.5$

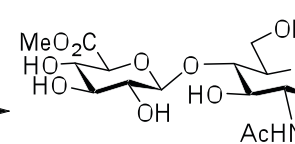

53
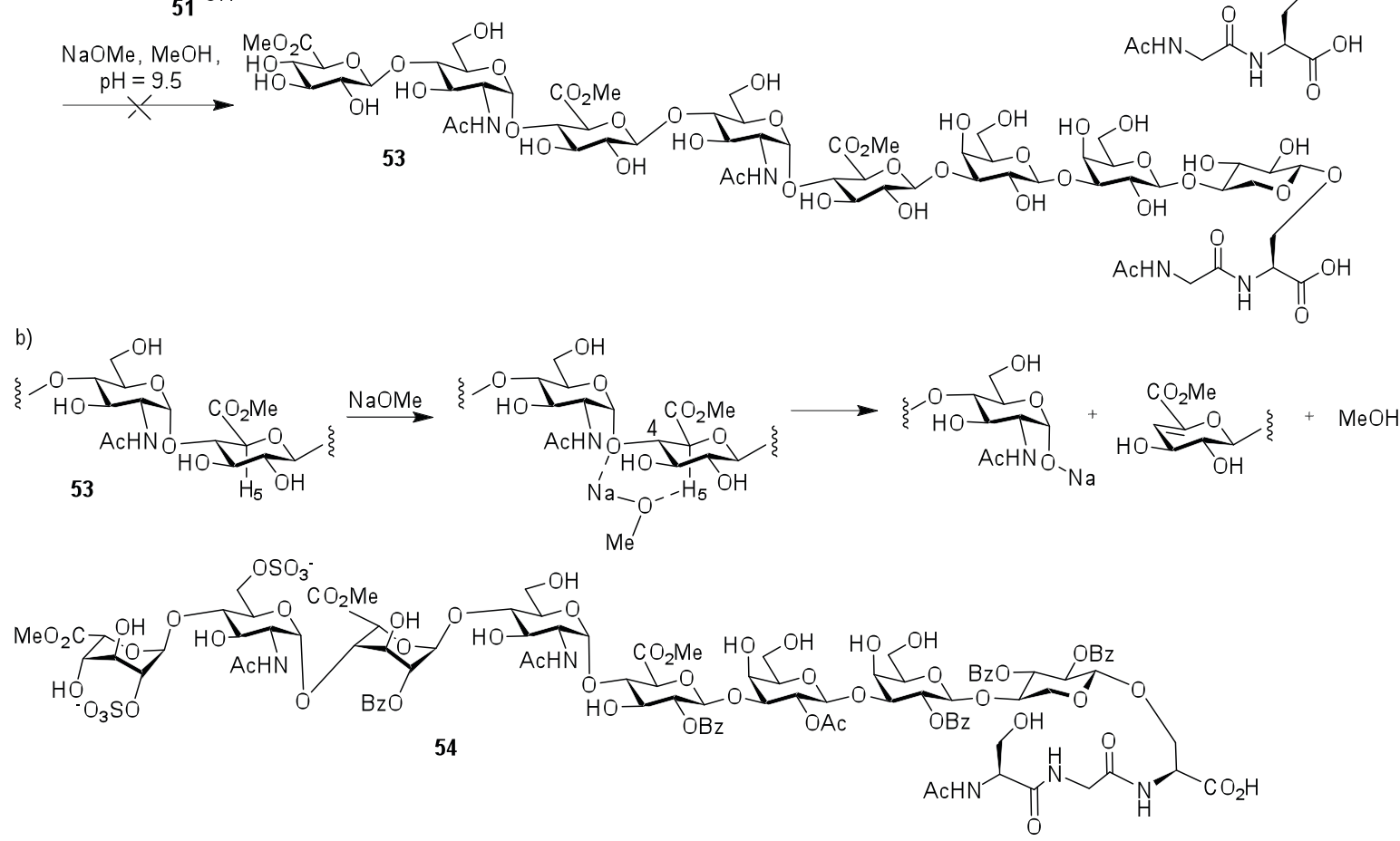

The base sensitivity of the glycopeptide suggests a less basic yet stronger nucleophile such as hydrazine ${ }^{78,110}$ would be needed for deacylation. A model glycopeptide $\mathbf{5 5}$ was treated with hydrazine, which successfully cleaved the Bz and Lev groups without affecting the sulfates or the glycan/peptide linkage. In order to apply the hydrazine reaction to syndecan-3 glycopeptides, the carboxylic acid moieties of uronic acids cannot be protected as esters during the hydrazine treatment to prevent the potential hydrazide formation. This consideration led to the design of a new route, where the full length glycopeptide $\mathbf{5 6}$ was to be assembled from two fragments: glycopeptides $\mathbf{5 7}$ and $\mathbf{5 8}$, which could be prepared through peptide coupling. The 
uronic methyl esters of $\mathbf{5 6}$ can be converted to free carboxylic acids by mild base treatment for subsequent hydrazinolysis.

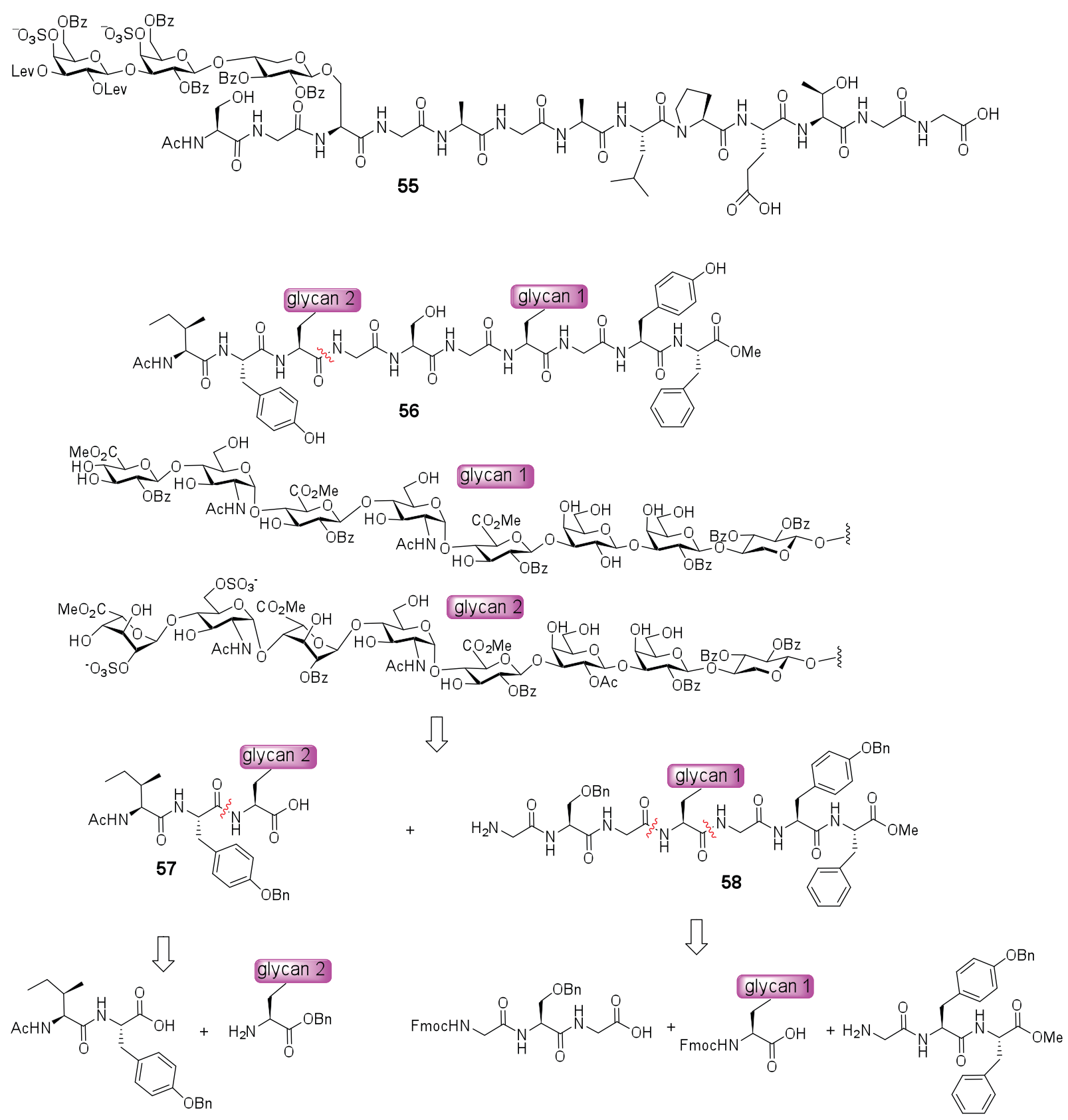

In order to synthesize glycopeptide $\mathbf{5 7}$, glycosyl serine $\mathbf{3}$ was transformed to octasaccharide $\mathbf{5 9}$ through conversion of azides to acetamides, Lev group removal by hydrazine acetate and sulfation of the free hydroxyl groups. ${ }^{111}$ The Fmoc group in octasaccharide $\mathbf{5 9}$ was removed and the resulting amine was coupled with dipeptide 60 to produce glycopeptide $\mathbf{6 1 .}$ The tyrosine hydroxyl group in the side chain of peptide $\mathbf{6 1}$ was protected with Bn, which can be 
deprotected under hydrogenation conditions. The benzyl ester in glycopeptide $\mathbf{6 1}$ was selectively removed under hydrogenation in the presence of $\mathrm{NH}_{4} \mathrm{OAc}^{112}$ leading to free carboxylic acid glycopeptide 57 (Scheme 8).

\section{Scheme 8}

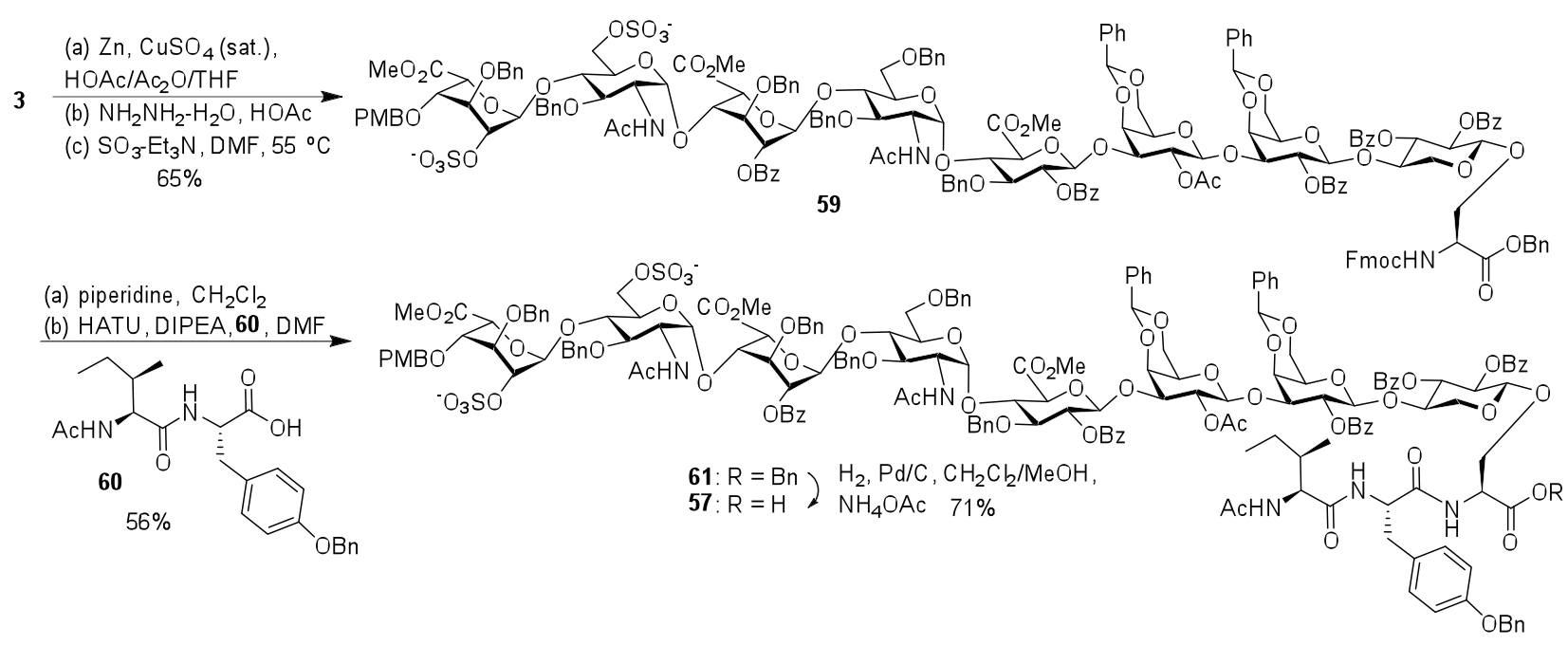

Similarly, hydrogenation of octasaccharide 4 in the presence of $\mathrm{NH}_{4} \mathrm{OAc}^{112}$ afforded glycopeptide 62 containing the free $C$-terminal carboxylic acid (Scheme 9). Peptide elongation with tripeptide 63 gave glycopeptide 64. Treatment of 64 with piperidine followed by coupling with tripeptide $\mathbf{6 5}$ and Fmoc deprotection led to the free amine bearing glycopeptide $\mathbf{5 8}$.

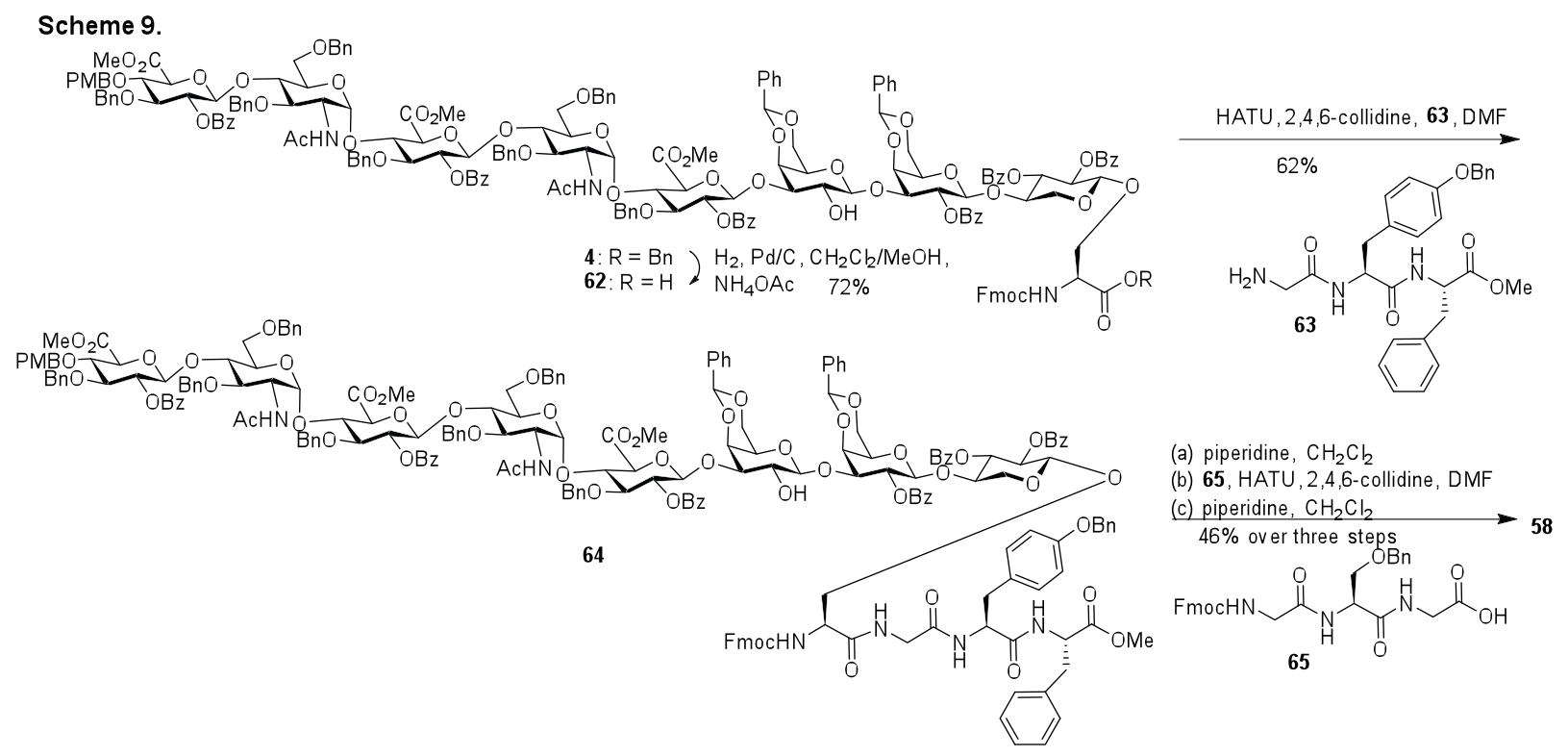


Glycopeptides $\mathbf{5 7}$ and $\mathbf{5 8}$ were united in a peptide coupling reaction promoted by $O$-(7azabenzotriazol-1-yl)- $N, N, N^{\prime}, N^{\prime}$-tetramethyluronium hexafluorophosphate (HATU) to generate glycopeptide 66 bearing two different glycans (Scheme 10). Glycopeptide 66 was hydrogenated with Pearlman's reagent or $\mathrm{Pd} / \mathrm{C}$ under atmospheric pressure of hydrogen gas in mixed solvents of $\mathrm{CH}_{2} \mathrm{Cl}_{2}$ and methanol to remove the benzyl ethers, $\mathrm{PMB}$ and benzylidene groups. However, no desired product 56 was obtained. It is possible that the partially deprotected glycopeptides formed during hydrogenation aggregated due to solubility changes preventing access to the palladium catalyst. Colloidal Pd nanoparticles were tested next as the Wong group reported that these nanoparticles could remove benzyl ethers from solid phase bound glycans. ${ }^{113}$ Various solvents including tetrahydrofuan, methanol/water and hexafluoro-isopropanol, were also examined to disrupt the potential aggregate. Other conditions tested included various $\mathrm{pH}$ values, reaction temperature and elevated hydrogen pressure. However, the desired compound $\mathbf{5 6}$ was not found with decomposition products observed in mass spectrometry analysis. The difficulty with glycopeptide $\mathbf{6 6}$ was not unique as several other glycopeptides bearing two heparan sulfate glycans decomposed as well when subjected to hydrogenation. Hojo, Nakahara and coworkers reported a procedure using low acidity triflic acid to remove benzyl ethers from $O$-sulfated glycopeptides. ${ }^{114}$ In our hands, this condition cleaved the $O$-sulfates from glycopeptide 66 without successful debenzylation.

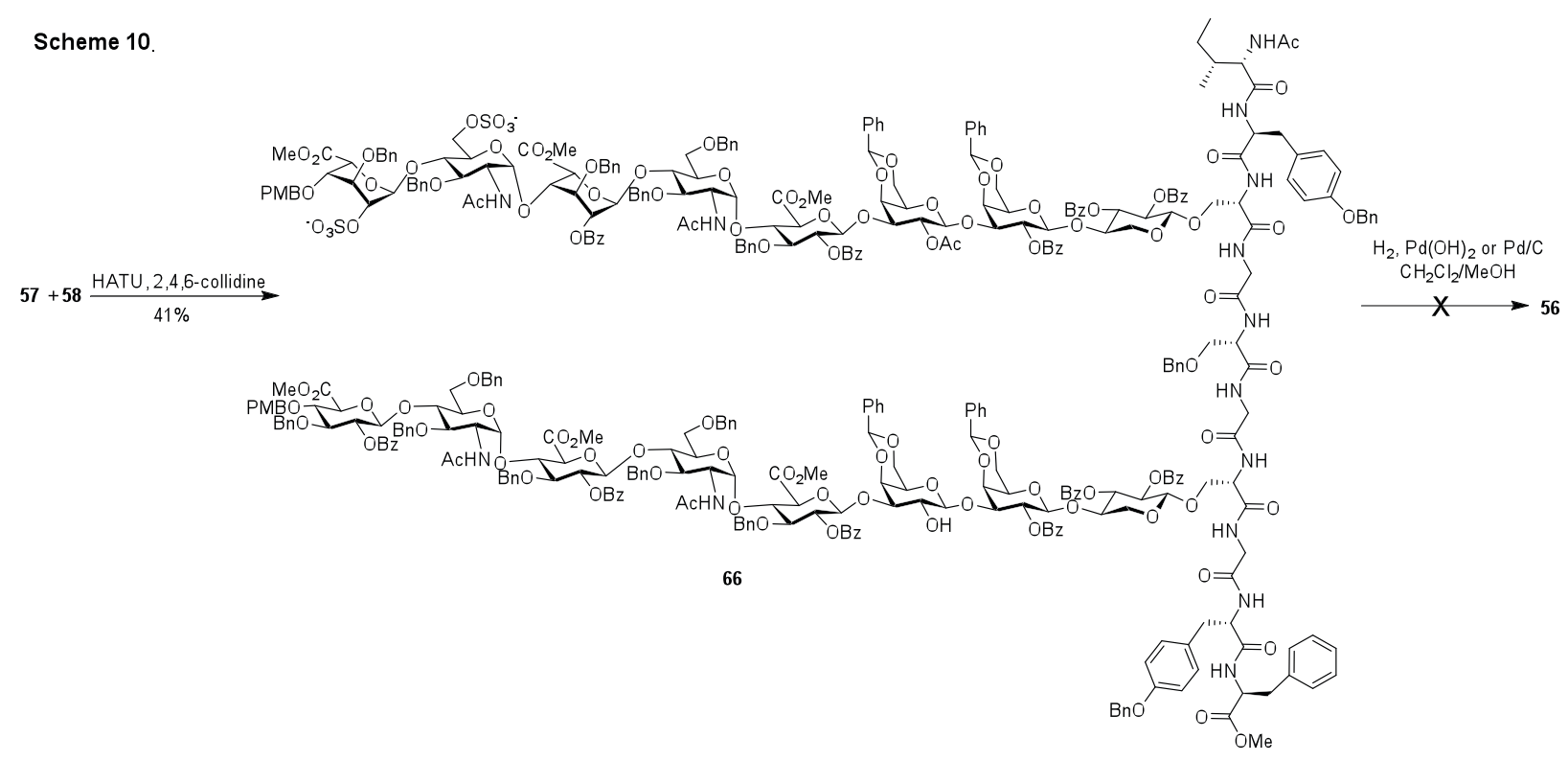




\section{Successful synthesis of glycopeptide 1}

Due to the unexpected difficulty in the hydrogenation of $\mathbf{6 6}$, an alternative was to perform hydrogenation on glycopeptides $\mathbf{6 1}$ and $\mathbf{5 8}$ bearing a single heparan sulfate chain. The iduronic acid containing non-sulfated glycopeptide 67 was tested first, which was prepared analogously to 61. Catalytic hydrogenation of compound 67 under a slightly acidic condition ( $\mathrm{pH} \sim 5.5)$ using Pearlman's catalyst went smoothly and gave the desired product 68 in quantitative yield (Scheme 11). Similarly, sulfated glycopeptide 61 was successfully hydrogenated yielding 69. The reason for the increase in fragility of glycopeptides bearing two heparan sulfate chains towards hydrogenation is not clear.

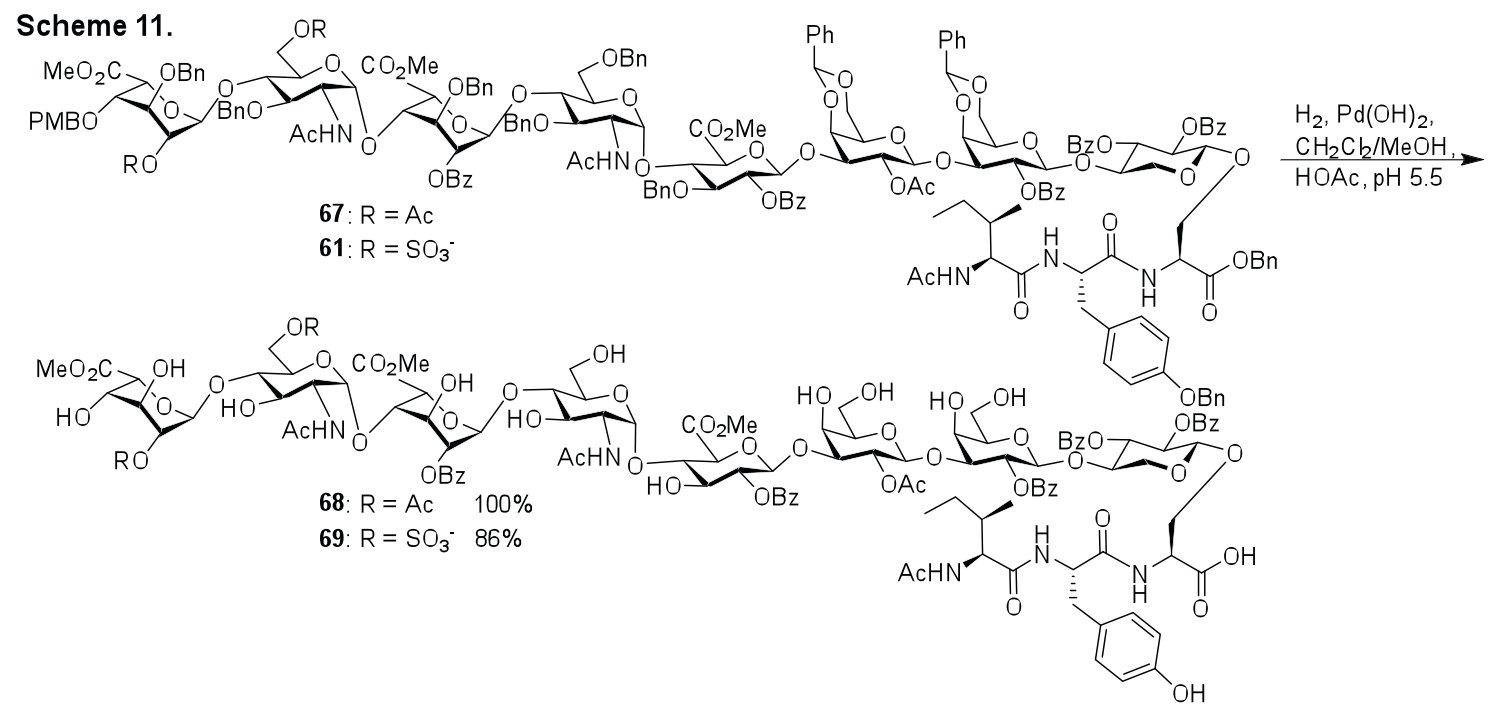

The hydrogenation of glycopeptide $\mathbf{5 8}$ was performed next to generate amine $\mathbf{7 0}$ (Scheme 12). This reaction was slower than those of $\mathbf{6 1}$ and $\mathbf{6 7}$ and needed to be closely monitored to prevent over-reduction. 70 was coupled with carboxylic acid 68 (2 eq) producing glycopeptide 71 in $46 \%$ yield. To complete the deprotection, the three methyl esters in 71 were cleaved by $\mathrm{LiOH}$ ( $\mathrm{pH} 9.5$ ) followed by hydrazine to afford the fully deprotected glycopeptide 2 in $72 \%$ yield over the two steps (Scheme 12). 


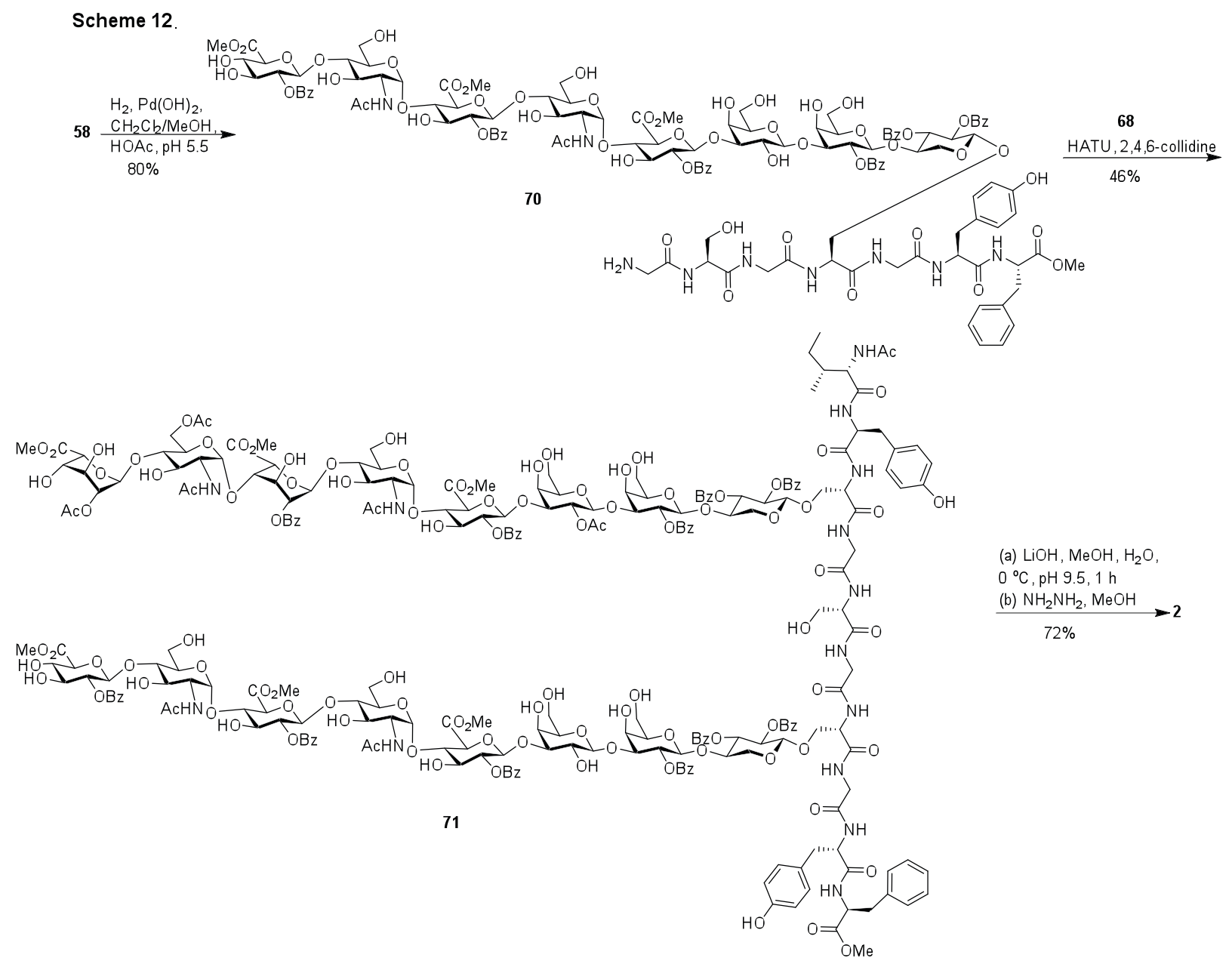

The synthesis of the sulfated glycopeptide 1 was tested next. When 2 eq of carboxylic acid 69 was utilized in the HATU mediated coupling with amine 70, the desired product 56 was observed, but contaminated with glycan 72 resulting from $\beta$-elimination of 69 (Scheme 13). The separation of $\mathbf{7 2}$ from $\mathbf{5 6}$ turned out to be very difficult. When 1.5 equiv of glycopeptide $\mathbf{6 9}$ was utilized, the coupling yield was much lower. 


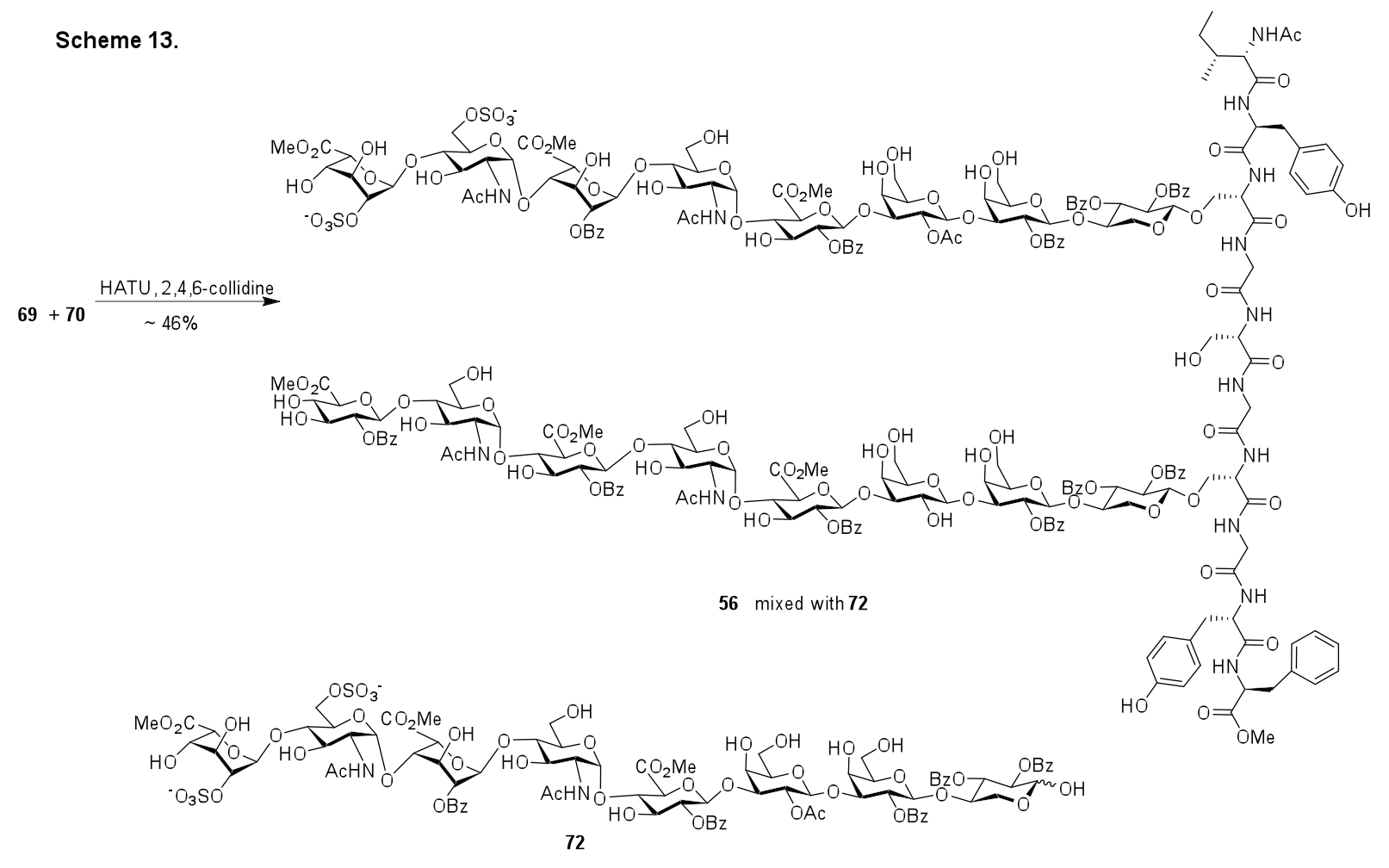

To overcome the elimination problem, we adjusted the sequence for peptide chain elongation by coupling carboxylic acid 69 with tripeptide 73 first (Scheme 14a). We envisioned the smaller tripeptide $\mathbf{7 3}$ should be a better nucleophile than amine 70. Indeed, the reaction of glycopeptide 69 with tripeptide 73 went smoothly with no $\beta$-elimination product $\mathbf{7 2}$, which led to glycopeptide 75 after hydrogenation. This suggests the formation of 72 (Scheme 13) was not because of the inherent instability of glycopeptide 56 under the peptide coupling condition. Rather, it was possibly due to the enhanced lability of the activated ester $\mathbf{7 6}$ formed between $\mathbf{7 1}$ and HATU towards $\beta$-elimination (Scheme 14b), which could outcompete the desired amide bond formation reaction with the more bulky and presumably less reactive amine $\mathbf{7 0 .}$ 

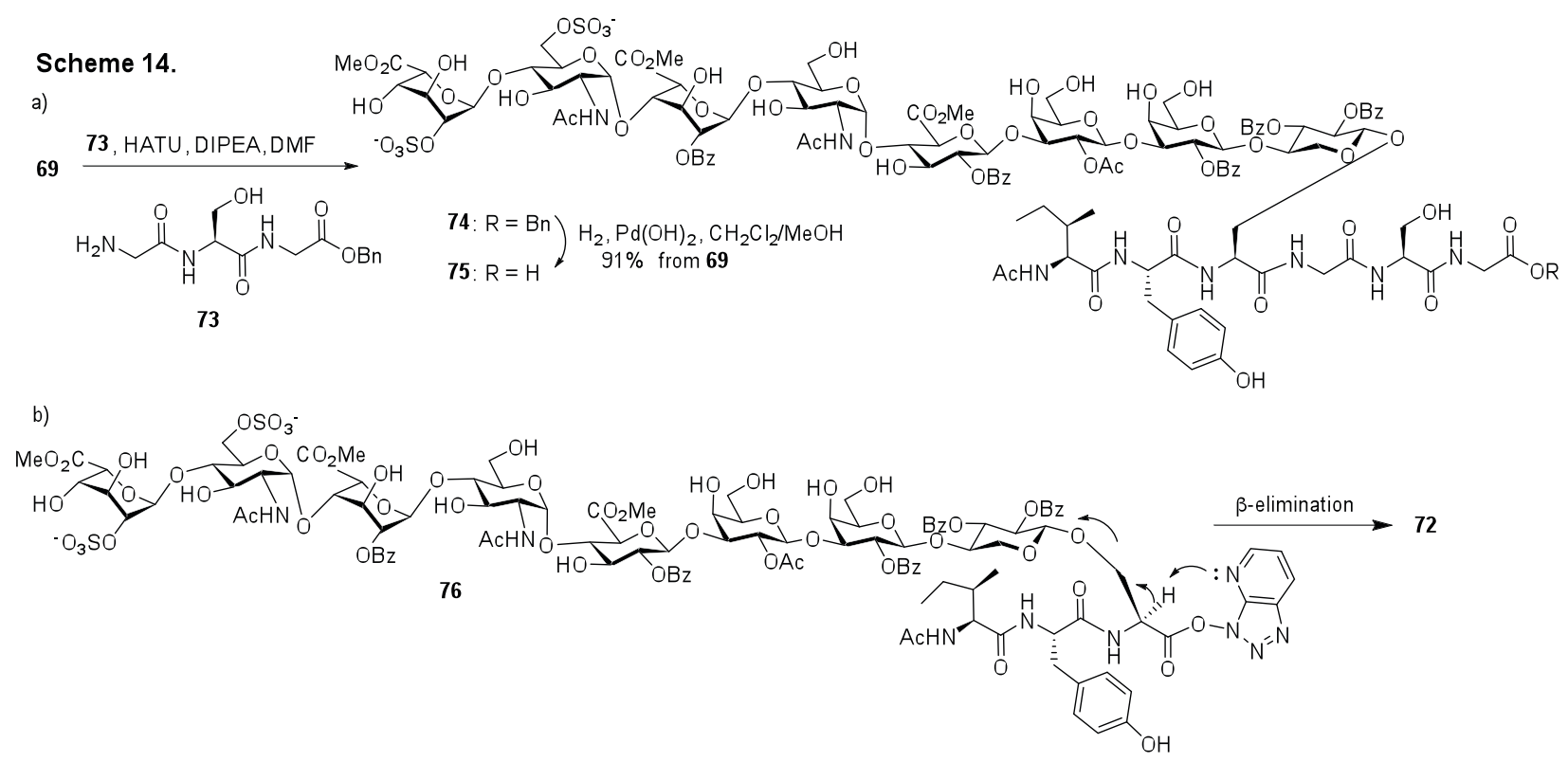

To complete the glycopeptide synthesis, amine $\mathbf{7 7}$ was needed. Catalytic hydrogenation of 64 catalyzed by $\mathrm{Pd}(\mathrm{OH})_{2}$ or $\mathrm{Pd} / \mathrm{C}$ proceeded very slowly (Scheme 15a). With prolonged reaction time, multiple side products due to methylation of the free $N$-terminus ${ }^{115}$ and reduction of phenyl rings were formed, which could not be separated from the desired product. To address this issue, an alternative route was explored by installing a protective group onto the $\mathrm{N}$-terminus, which is stable under hydrogenation condition and yet known to be removable under mild conditions. Several amine protective groups including trifluoroacetamide (TFA), 2trimethylsilylethoxycarbonyl (Teoc) ${ }^{116}$ and 2-pyridylethoxycarbonyl (Pyoc) ${ }^{117}$ were examined. Global hydrogenolysis went smoothly on the TFA and Teoc protected glycosyl serine, while Pyoc protected one gave multiple unidentified side products. After peptide coupling leading to compounds 78 and $\mathbf{7 9}$, we focused on deprotection to generate the free amine. However, with 78, TFA could not be removed under basic or $\mathrm{NaBH}_{4}$ reductive condition ${ }^{118}$ without affecting the methyl esters in the molecule. The Teoc group in $\mathbf{7 9}$ could not be cleaved by HF/pyridine. Treatment of $\mathbf{7 9}$ with tetrabutylammonium fluoride (TBAF) led to the cleavage of glycan chain. These unsuccessful attempts prompted us to re-examine the substrate for hydrogenation. After many trials, a viable route was established by first removing the Fmoc from glycopeptide 64 (Scheme 15b). The resulting amine was successfully hydrogenated under a slightly acidic condition (pH 6 with the addition of $\left.\mathrm{CCl}_{3} \mathrm{CO}_{2} \mathrm{H}\right) .{ }^{119}$ No over-reduction or amine alkylation side 
products were observed. The usage of trichloroacetic acid was important as the reaction was not successful with acetic acid.

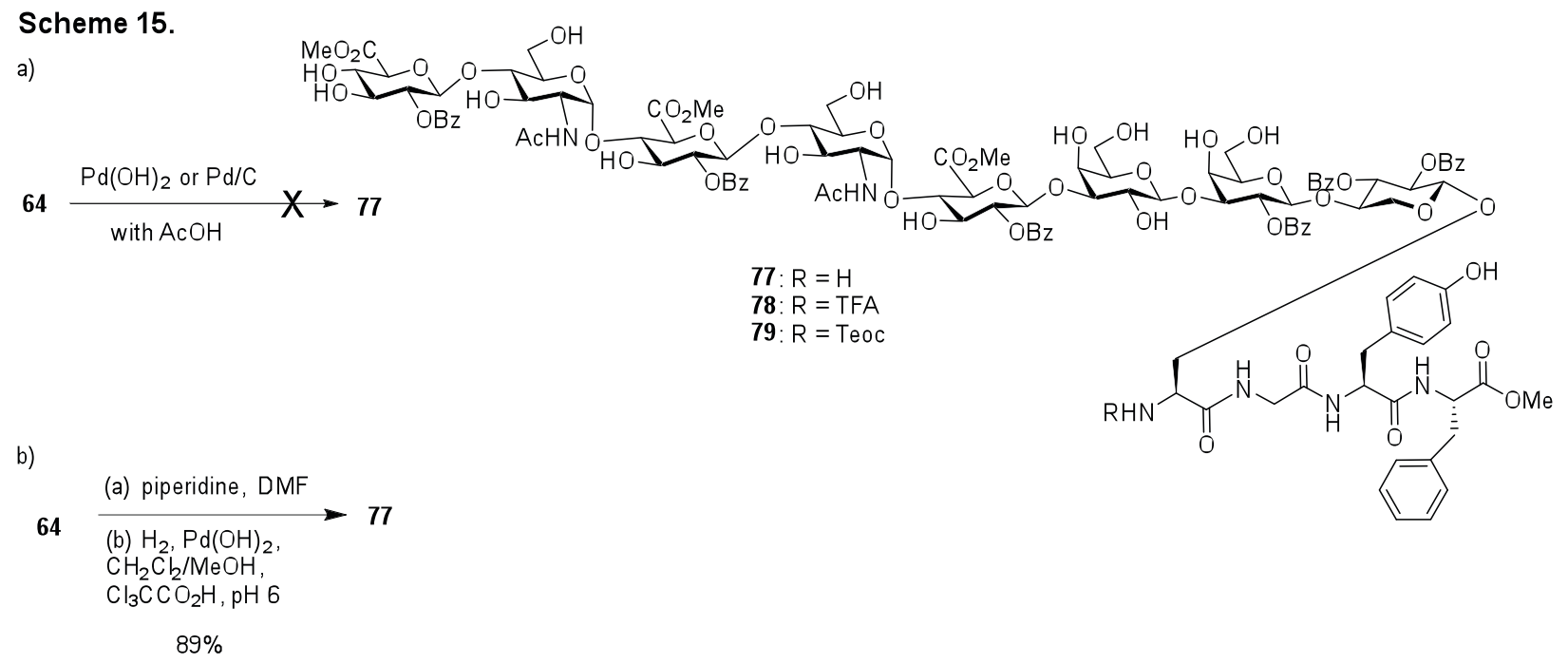

With amine $\mathbf{7 7}$ in hand, its coupling with $\mathbf{7 5}$ was carried out with 1.3 eq of $\mathbf{7 5}$ and HATU providing 56 in 58\% yield (Scheme 16). No $\beta$-elimination side product 72 was observed from this reaction, which was consistent with the formation of 74. Final deprotection of 56 was performed under a mild basic condition. The sulfated glycan chain was very sensitive to base as $\mathrm{pH} 9.5 \mathrm{LiOH}$ led to partial chain cleavage. Instead, the methyl ester removal was performed at pH 9.0 with frequent monitoring using mass spectrometry, which was followed by hydrazinolysis to afford glycopeptide 1 in $82 \%$ yield. 


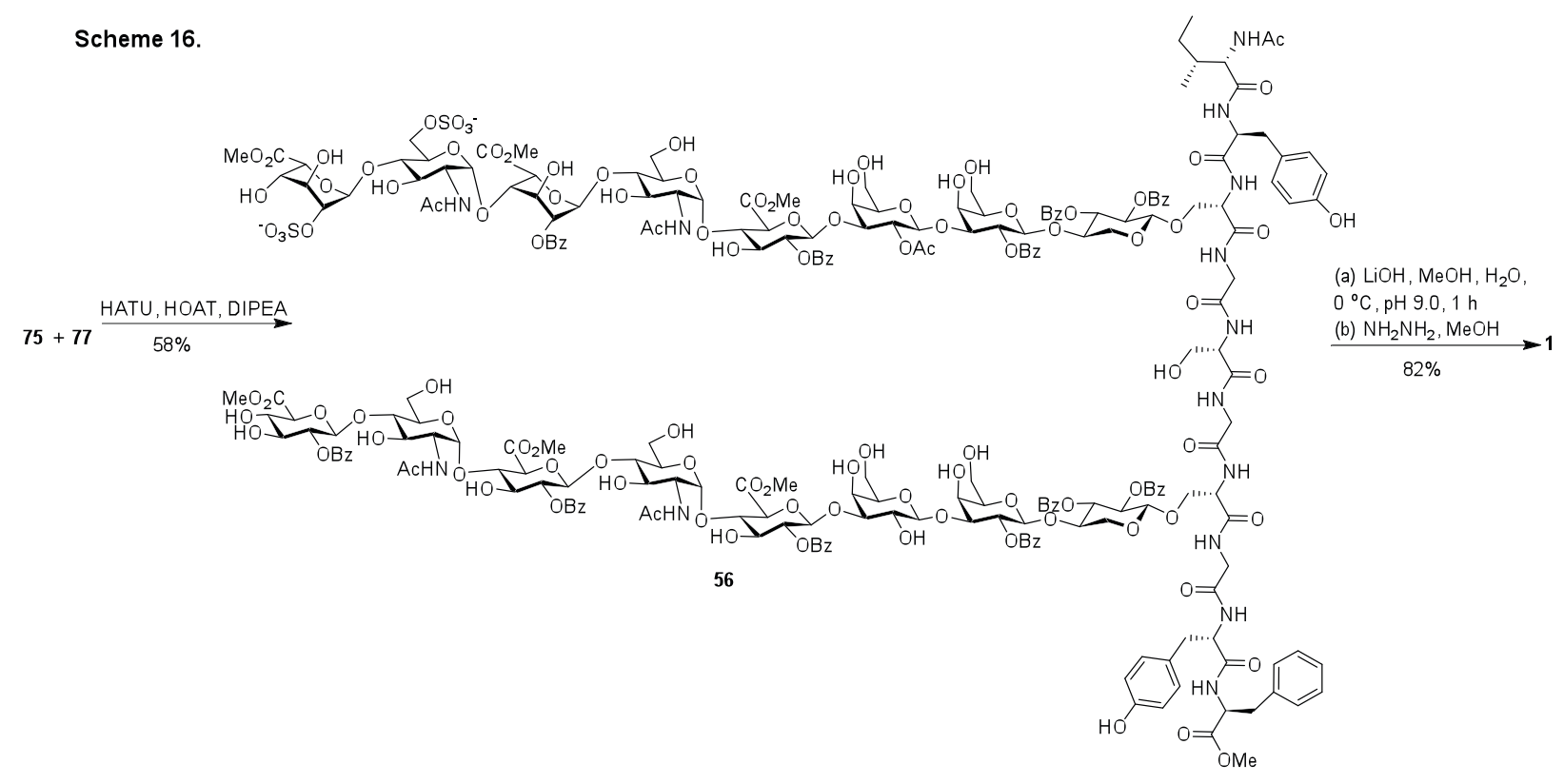

\section{Conclusion}

A successful strategy was developed for the assembly of syndecan-3 (53-62) glycopeptides bearing two heparan sulfate chains. Many obstacles were encountered during the syntheses of these highly complex molecules. For construction of the glycan chains, among many potential routes, we found the difficult B/C glycosyl linkages should be formed early due to higher reactivities of the monosaccharide building blocks. Furthermore, as the size of the molecule grows larger, unique reactivity and stability problems can emerge as evident from the instability of glycopeptides containing two heparan sulfate chains to the catalytic hydrogenation condition. To overcome this obstacle, the hydrogenation reaction was performed on the glycopeptide bearing a single glycan chain. Performing the hydrogenation reaction with addition of trichloroacetic acid at pH6 was found to significantly improve the yield and suppress side product formation. Another challenge encountered was the propensity of glycopeptide bearing glycan chain at the $\mathrm{C}$-terminus to undergo competing $\beta$-elimination during peptide elongation reaction with larger and less reactive amine partners. This was overcome by varying the peptide coupling sequences. Following the union of partially deprotected fragments, the final deprotection of the glycopeptide required the cleavage of all ester protective groups, which was accomplished by mild base treatment ( $\mathrm{pH}$ 9.0) followed by hydrazinolysis. The hydrazinolysis procedure was critical to ensure complete removal of all acyl protective groups without the 
undesired $\beta$-elimination or cleavage of the highly sensitive glycan chain. Efforts are ongoing to extend the peptide backbone and glycan chains of glycopeptides as well as applying the strategy to synthesis of other glycosaminoglycan family glycopeptides bearing multiple heparan sulfate chains.

Acknowledgement: This work was supported by the National Science Foundation (CHE 1507226) and the National Institute of General Medical Sciences, NIH (R01GM072667, U01 GM116262 and U01 GM102137).

Supporting information: Complete experimental procedures and characterizations are provided, including ${ }^{1} \mathrm{H}$ and ${ }^{13} \mathrm{C}$ NMR spectra of all new compounds.

Notes: The authors declare no competing financial interest.

\section{References:}

(1) Apweiler, R.; Hermjakob, H.; Sharon, N. Biochem. Biophys. Acta 1999, 1473, 4-8.

(2) Dwek, R. A. Chem. Rev. 1996, 96, 683-720.

(3) Helenius, A.; Aebi, M. Science 2005, 291, 2364-2369.

(4) Varki, A. Glycobiology 1993, 3, 97-130.

(5) Pratt, M. R.; Bertozzi, C. R. Chem. Soc. Rev. 2005, 34, 58-68.

(6) Bernfield, M.; Götte, M.; Park, P. W.; Reizes, O.; Fitzgerald, M. L.; Lincecum, J.; Zako, M. Annu. Rev. Biochem. 1999, 68, 729-777.

(7) Piontek, C.; Varón Silva, D.; Heinlein, C.; Pöhner, C.; Mezzato, S.; Ring, P.; Martin, A.; Schmid, F. X.; Unverzagt, C. Angew. Chem. Int. Ed. 2009, 48, 1941-1945.

(8) Wang, P.; Dong, S.; Shieh, J.-H.; Peguero, E.; Hendrickson, R.; Moore, M. A. S.; Danishefsky, S. J. Science 2013, 342, 1357-1360. 
(9) Murakami, M.; Kiuchi, T.; Nishihara, M.; Tezuka, K.; Okamoto, R.; Izumi, M.; Kajihara, Y. Sci. Adv. 2016, 2, e1500678.

(10) Xu, C.; Lam, H. Y.; Zhang, Y.; Li, X. Chem. Commun. 2013, 49, 6200-6202.

(11) Izumi, R.; Matsushita, T.; Fujitani, N.; Naruchi, K.; Shimizu, H.; Tsuda, S.; Hinou, H.; Nishimura, S.-I. Chem. Eur. J. 2013, 19, 3913-3920.

(12) Cai, H.; Chen, M.-S.; Sun, Z.-Y.; Zhao, Y.-F.; Kunz, H.; Li, Y.-M. Angew. Chem. Int. Ed. 2013, 52, 6106-6110.

(13) Ullmann, V.; Raedisch, M.; Boos, I.; Freund, J.; Poehner, C.; Schwarzinger, S.; Unverzagt, C. Angew. Chem. Int. Ed. 2012, 51, 11566-11570.

(14) Wilkinson, B. L.; Stone, R. S.; Capicciotti, C. J.; Thaysen-Andersen, M.; Matthews, J. M.; Packer, N. H.; Ben, R. N.; Payne, R. J. Angew. Chem. Int. Ed. 2012, 51, 3606-3610.

(15) Sakamoto, I.; Tezuka, K.; Fukae, K.; Ishii, K.; Taduru, K.; Maeda, M.; Ouchi, M.; Yoshida, K.; Nambu, Y.; Igarashi, J.; Hayashi, N.; Tsuji, T.; Kajihara, Y. J. Am. Chem. Soc. 2012, 134, 5428-5431.

(16) Wang, P.; Dong, S.; Brailsford, J. A.; Iyer, K.; Townsend, S. D.; Zhang, Q.; Hendrickson, R. C.; Shieh, J.; Moore, M. A. S.; Danishefsky, S. J. Angew. Chem. Int. Ed. 2012, 51, 1157611584.

(17) Chen, R.; Tolbert, T. J. J. Am. Chem. Soc. 2010, 132, 3211-3216.

(18) Sanki, A. K.; Talan, R. S.; Sucheck, S. J. J. Org. Chem. 2009, 74, 1886-1896.

(19) Crich, D.; Sasaki, K.; Rahaman, M. Y.; Bowers, A. A. J. Org. Chem. 2009, 74, 3886-3893.

(20) Yang, Y.-Y.; Ficht, S.; Brik, A.; Wong, C.-H. J. Am. Chem. Soc. 2007, 129, 7690-7701.

(21) Yamamoto, N.; Tanabe, Y.; Okamoto, R.; Dawson, P. E.; Kajihara, Y. J. Am. Chem. Soc. 2008, 130, 501-510. 
(22) Shao, N.; Xue, J.; Guo, Z. Angew. Chem. Int. Ed. 2004, 43, 1569-1573.

(23) Shin, Y.; Winans, K. A.; Backes, B. J.; Kent, S. B. H.; Ellman, J. A.; Bertozzi, C. R. J. Am. Chem. Soc. 1999, 121, 11684-11689.

(24) Hojo, H.; Tanaka, H.; Hagiwara, M.; Asahina, Y.; Ueki, A.; Katayama, H.; Nakahara, Y.; Yoneshige, A.; Matsuda, J.; Ito, Y.; Nakahara, Y. J. Org. Chem. 2012, 77, 9437-9446.

(25) Wu, Z.; Guo, X.; Wang, Q.; Swarts, B. M.; Guo, Z. J. Am. Chem. Soc. 2010, 132, 15671571.

(26) Heidecke, C. D.; Ling, Z.; Bruce, N. C.; Moir, J. W. B.; Parsons, T. B.; Fairbanks, A. J. ChemBiochem 2008, 9, 2045-2051.

(27) Li, B.; Zeng, Y.; Hauser, S.; Song, H.; Wang, L.-X. J. Am. Chem. Soc. 2005, 127, 96929693.

(28) Takano, Y.; Hojo, H.; Kojima, H.; Nakahara, Y. Org. Lett. 2004, 6, 3135-3138.

(29) George, S. K.; Schwientek, T.; Holm, B.; Reis, C. A.; Clausen, H.; Kihlberg, J. J. Am. Chem. Soc. 2001, 123, 11117-11125.

(30) Witte, K.; Sears, P.; Wong, C.-H. J. Am. Chem. Soc. 1997, 119, 2114-2118.

(31) Unverzagt, C.; Kajihara, Y. Chem. Soc. Rev. 2013, 42, 4408-4420.

(32) Siman, P.; Brik, A. Org. Biomol. Chem. 2012, 10, 5684-5697.

(33) Payne, R. J.; Wong, C.-H. Chem. Commun. 2010, 46, 21-43.

(34) Gamblin, D. P.; Scanlan, E. M.; Davis, B. G. Chem. Rev. 2009, 109, 131-163.

(35) Wang, L.-X. Carbohydr. Res. 2008, 343, 1509-1522 and references cited therein.

(36) Hojo, H.; Nakahara, Y. Biopolymers 2007, 88, 308-324.

(37) Herzner, H.; Reipen, T.; Schultz, M.; Kunz, H. Chem. Rev. 2000, 100, 4495-4537.

(38) Meldal, M.; Bock, K. Glycoconjugate J. 1994, 11, 59-63. 
(39) Dulaney, S. B.; Huang, X. Adv. Carbohydr. Chem. Biochem. 2012, 67, 95-136 and references cited therein.

(40) Noti, C.; Seeberger, P. H. In Chemistry and Biology of Heparin and Heparan Sulfate; Garg, H. G., Linhardt, R. J., Hales, C. A., Eds.; Elsevier: Oxford, 2005, p 79-142.

(41) Petitou, M.; van Boeckel, C. A. A. Angew. Chem. Int. Ed. 2004, 43, 3118-3133 and references cited therein.

(42) Codée, J. D. C.; Overkleeft, H. S.; van der Marel, G. A.; van Boeckel, C. A. A. Drug Discovery Today: Technol.2004, 1, 317-326.

(43) Poletti, L.; Lay, L. Eur. J. Org. Chem. 2003, 2999-3024.

(44) Karst, N. A.; Linhardt, R. J. Curr. Med. Chem. 2003, 10, 1993-2031.

(45) Hansen, S. U.; Miller, G. J.; Cliff, M. J.; Jayson, G. C.; Gardiner, J. M. Chem. Sci. 2015, 6, 6158-6164.

(46) Hansen, S. U.; Miller, G. J.; Cole, C.; Rushton, G.; Avizienyte, E.; Jayson, G. C.; Gardiner, J. M. Nature Commun. 2013, 4, doi:10.1038/ncomms3016.

(47) Sheng, G. J.; Oh, Y. I.; Chang, S.-K.; Hsieh-Wilson, L. C. J. Am. Chem. Soc. 2013, 135, 10898-10901.

(48) Xu, Y.; Wang, Z.; Liu, R.; Bridges, A. S.; Huang, X.; Liu, J. Glycobiology 2012, 22, 96-106 and references cited therein.

(49) Xu, Y.; Masuko, S.; Takeiddin, M.; Xu, H.; Liu, R.; Jing, J.; Mousa, S. A.; Linhardt, R. J.; Liu, J. Science 2011, 334, 498-501.

(50) Hu, Y.-P.; Lin, S.-Y.; Huang, C.-Y.; Zulueta, M. M. L.; Liu, J.-Y.; Chang, W.; Hung, S.-C. Nature Chem. 2011, 3, 557-563. 
(51) Tiruchinapally, G.; Yin, Z.; El-Dakdouki, M.; Wang, Z.; Huang, X. Chem. Eur. J. 2011, 17, 10106-10112.

(52) Czechura, P.; Guedes, N.; Kopitzki, S.; Vazquez, N.; Martin-Lomas, M.; Reichardt, N.-C. Chem. Commun. 2011, 47, 2390-2392.

(53) Wang, Z.; Xu, Y.; Yang, B.; Tiruchinapally, G.; Sun, B.; Liu, R.; Dulaney, S.; Liu, J.; Huang, X. Chem. Eur. J. 2010, 16, 8365-8375.

(54) Arungundram, S.; Al-Mafraji, K.; Asong, J.; Leach, F. E.; Amster, I. J.; Venot, A.; Turnbull, J. E.; Boons, G. J. J. Am. Chem. Soc. 2009, 131, 17394-17405.

(55) Baleux, F.; Loureiro-Morais, L.; Hersant, Y.; Clayette, P.; Arenzana-Seisdedos, F.; Bonnaffé, D.; Lortat-Jacob, H. Nat. Chem. Biol. 2009, 5, 743-748 and references cited therein.

(56) Chen, J.; Zhou, Y.; Chen, C.; Xu, W.; Yu, B. Carbohydr. Res. 2008, 343, 2853-2862.

(57) Dilhas, A.; Lucas, R.; Loureiro-Morais, L.; Hersant, Y.; Bonnaffe, D. J. Comb. Chem. 2008, $10,166-169$.

(58) Tatai, J.; Fügedi, P. Tetrahedron 2008, 64, 9865-9873.

(59) Polat, T.; Wong, C.-H. J. Am. Chem. Soc. 2007, 129, 12795-12800.

(60) Noti, C.; de Paz, J. L.; Polito, L.; Seeberger, P. H. Chem. Eur. J. 2006, 12, 8664-8686.

(61) Codée, J. D. C.; Stubba, B.; Schiattarella, M.; Overkleeft, H. S.; van Boeckel, C. A. A.; van Boom, J. H.; van der Marel, G. A. J. Am. Chem. Soc. 2005, 127, 3767-3773.

(62) de Paz, J. L.; Martin-Lomas, M. Eur.J. Org. Chem. 2005, 1849-1858 and references cited therein.

(63) Fan, R.-H.; Achkar, J.; Hernandez-Torres, J. M.; Wei, A. Org. Lett. 2005, 7, 5095-5098.

(64) Ojeda, R.; Terenti, O.; de, P. J.-L.; Martin-Lomas, M. Glycoconjugate J. 2004, 21, 179-195.

(65) Lucas, R.; Hamza, D.; Lubineau, A.; Bonnaffé, D. Eur. J. Org. Chem. 2004, 2107-2117. 
(66) Poletti, L.; Fleischer, M.; Vogel, C.; Guerrini, M.; Torri, G.; Lay, L. Eur. J. Org. Chem. 2001, 2727-2734.

(67) Petitou, M.; Herault, J.-P.; Bernat, A.; Driguez, P.-A.; Duchaussoy, P.; Lormeau, J.-C.; Herbert, J.-M. Nature 1999, 398, 417-422.

(68) Sinaÿ, P.; Jacquinet, J. C.; Petitou, M.; Duchaussoy, P.; Lederman, I.; Choay, J.; Torri, G. Carbohydr. Res. 1984, 132, C5-C9.

(69) Ait-Mohand, K.; Lopin-Bon, C.; Jacquinet, J. C. Carbohydr. Res. 2012, 353, 33-48.

(70) Huang, T.-Y.; Zulueta, M. M. L.; Hung, S.-C. Org. Lett. 2011, 13, 1506-1509.

(71) Tamura, J.-i.; Nakamura-Yamamoto, T.; Nishimura, Y.; Mizumoto, S.; Takahashi, J.; Sugahara, K. Carbohydr. Res. 2010, 345, 2115-2123.

(72) Shimawaki, K.; Fujisawa, Y.; Sato, F.; Fujitani, N.; Kurogochi, M.; Hoshi, H.; Hinou, H.; Nishimura, S.-I. Angew. Chem., Int. Ed. 2007, 46, 3074-3079.

(73) Thollas, B.; Jacquinet, J.-C. Org. Biomol. Chem. 2004, 2, 434-442.

(74) Tamura, J.; Yamaguchi, A.; Tanaka, J. Bioorg. Med. Chem. Lett. 2002, 12, 1901-1903.

(75) Allen, J. G.; Fraser-Reid, B. J. Am. Chem. Soc. 1999, 121, 468-469.

(76) Yasukochi, T.; Fukase, K.; Suda, Y.; Takagaki, K.; Endo, M.; Kusumoto, S. Bull. Chem. Soc. Jpn. 1997, 70, 2719-2725.

(77) Neumann, K. W.; Tamura, J.; Ogawa, T. Glycoconjugate J. 1996, 13, 933-936.

(78) Rio, S.; Beau, J. M.; Jacquinet, J. C. Carbohydr. Res. 1994, 255, 103-124.

(79) Chen, L.; Kong, F. Carbohydr. Res. 2002, 337, 1373-1380.

(80) Yoshida, K.; Yang, B.; Yang, W.; Zhang, Z.; Zhang, J.; Huang, X. Angew. Chem. Int. Ed. 2014, 53, 9051-9058.

(81) Tkachenko, E.; Rhodes, J. M.; Simons, M. Circ. Res. 2005, 96, 488-500. 
(82) Zimmermann, P.; David, G. FASEB J. 1999, 13, S91-S100.

(83) Bespalov, M. M.; Sidorova, Y. A.; Tumova, S.; Ahonen-Bishopp, A.; Magalhaes, A. C.; Kulesskiy, E.; Paveliev, M.; Rivera, C.; Rauvala, H.; Saarma, M. J. Cell Biol. 2011, 192, 153169.

(84) Pisconti, A.; Cornelison, D. D. W.; Olguin, H. C.; Antwine, T. L.; Olwin, B. B. J. Cell Biol. 2010, 190, 427-441.

(85) Casar, J. C.; Cabello-Verrugio, C.; Olguin, H.; Aldunate, R.; Inestrosa, N. C.; Brandan, E. J. Cell Sci. 2004, 117, 73-84.

(86) Cornelison, D. D. W.; Wilcox-Adelman, S. A.; Goetinck, P. F.; Rauvala, H.; Rapraeger, A. C.; Olwin, B. B. Genes Dev. 2004, 18, 2231-2236.

(87) Kosher, R. A. Microsc. Res. Tech. 1998, 43, 123-130.

(88) de Witte, L.; Bobardt, M.; Chatterji, U.; Degeest, G.; David, G.; Geijtenbeek, T. B.; Gallay, P. Proc.Natl. Acad.Sci. USA 2007, 104, 19464-19469.

(89) Gould, S. E.; Upholt, W. B.; Kosher, R. A. Dev. Biol. 1995, 168, 438-451.

(90) Gould, S. E.; Upholt, W. B.; Kosher, R. A. Proc. Natl. Acad. Sci. USA 1992, 89, 3271-3275.

(91) Chen, X.-T.; Sames, D.; Danishefsky, S. J. J. Am. Chem. Soc. 1998, 120, 7760-7769.

(92) Van den Bos, L. J.; Codee, J. D. C.; Van der Toorn, J. C.; Boltje, T. J.; Van Boom, J. H.; Overkleeft, H. S.; Van der Marel, G. A. Org. Lett. 2004, 6, 2165-2168.

(93) Blatter, G.; Jacquinet, J.-C. Carbohydr. Res. 1996, 288, 109-125.

(94) Huang, L.; Huang, X. Chem. Eur. J. 2007, 13, 529-540.

(95) Huang, L.; Teumelsan, N.; Huang, X. Chem. Eur. J. 2006, 12, 5246-5252.

(96) Huang, X.; Huang, L.; Wang, H.; Ye, X.-S. Angew. Chem. Int. Ed. 2004, 43, 5221-5224.

(97) Crich, D.; Smith, M.; Yao, Q.; Picione, J. Synthesis 2001, 323-326. 
(98) Miermont, A.; Zeng, Y.; Jing, Y.; Ye, X.-S.; Huang, X. J. Org. Chem. 2007, 72, 8958-8961.

(99) Liao, L.; Auzanneau, F.-I. J. Org. Chem. 2005, 70, 6265-6273.

(100) Bock, K.; Pedersen, C. J. Chem. Soc., Perkin Trans. 2 1974, $293-297$.

(101) Zeng, Y.; Wang, Z.; Whitfield, D.; Huang, X. J. Org. Chem. 2008, 73, 7952-7962.

(102) Koeller, K. M.; Wong, C.-H. Chem. Rev. 2000, 100, 4465-4493 and references cited therein.

(103) Zhang, Z.; Ollman, I. R.; Ye, X.-S.; Wischnat, R.; Baasov, T.; Wong, C.-H. J. Am. Chem. Soc. 1999, 121, 734-753.

(104) Vohra, Y.; Buskas, T.; Boons, G.-J. J. Org. Chem. 2009, 74, 6064-6071.

(105) Yang, B.; Yoshida, K.; Yin, Z.; Dai, H.; Kavunja, H.; El-Dakdouki, M. H.; Sungsuwan, S.;

Dulaney, S. B.; Huang, X. Angew. Chem. Int. Ed. 2012, 51, 10185-10189.

(106) Borgia, J. A.; Malkar, N. B.; Abbasi, H. U.; Fields, G. B. J. Biomol. Tech. 2001, 12, 44-68. (107) Sjölin, P.; Elofsson, M.; Kihlberg, J. J. Org. Chem. 1996, 61, 560-565.

(108) Vuljanic, T.; Bergquist, K.-E.; Clausen, H.; Roy, S.; Kihlberg, J. Tetrahedron 1996, 52, 7983-8000.

(109) Gao, J.; Thomas, D. A.; Sohn, C. H.; Beauchamp, J. L. J. Am. Chem. Soc. 2013, 135, 10684-10692.

(110) Glunz, P. W.; Hintermann, S.; Williams, L. J.; Schwarz, J. B.; Kuduk, S. D.; Kudryashov, V.; Lloyd, K. O.; Danishefsky, S. J. J. Am. Chem. Soc. 2000, 122, 7273-7279.

(111) Al-Horani, R. A.; Desai, U. R. Tetrahedron 2010, 66, 2907-2918 and references cited therein.

(112) Kim, K. S.; Kim, J. H.; Lee, Y. J.; Lee, Y. J.; Park, J. J. Am. Chem. Soc. 2001, 123, 84778481. 
(113) Kanie, O.; Grotenbreg, G.; Wong, C.-H. Angew. Chem. Int. Ed. 2000, 39, 4545-4547.

(114) Kawahira, K.; Tanaka, H.; Ueki, A.; Nakahara, Y.; Hojo, H.; Nakahara, Y. Tetrahedron 2009, 65, 8143-8153.

(115) Xu, C.-P.; Xiao, Z.-H.; Zhuo, B.-Q.; Wang, Y.-H.; Huang, P.-Q. Chem. Commun. 2010, $46,7834-7836$.

(116) Shute, R. E.; Rich, D. H. Synthesis 1987, 346-348.

(117) Kunz, H.; Birnbach, S.; Wernig, P. Carbohydr. Res. 1990, 202, 207-223.

(118) Weygand, F.; Frauendorfer, E. Chem. Ber. 1970, 103, 2437-2449.

(119) Boger, D. L.; Kim, S. H.; Mori, Y.; Weng, J.-H.; Rogel, O.; Castle, S. L.; McAtee, J. J. J. Am. Chem. Soc. 2001, 123, 1862-1871. 